Rakenteiden Mekaniikka (Journal of Structural Mechanics)

Vol. 51, No 1, 2018, pp. 55-80

http://rakenteidenmekaniikka.journal.fi/index

https:/doi.org/10.23998/rm.68954

(C)Author(s) 2018.

Open access under CC BY-SA 4.0 license.

\title{
Numerical studies on vibration propagation and damping test $\mathrm{V} 1$
}

\author{
Arja Saarenheimo ${ }^{1}$, Michael Borgerhoff, Kim Calonius, Anthony Darraba, \\ Alexandre Hamelin, Sara Ghadimi Khasraghy, Amin Karbassi, Christian Schneeberger, \\ Matthias Stadler, Markku Tuomala and Pekka Välikangas
}

Summary. A new type of test series considering vibration propagation in a reinforced concrete structure has been carried out at VTT. Experimental results are utilized in verifying computational methods. Five finite element (FE) programs were used in computations: Abaqus, Europlexus, LSDYNA, SOFiSTiK and an in-house code (IHC). The calculated results, such as accelerations, displacements, their response spectra and strains, are compared with experimental measurements. Calculated results follow reasonable well test results in main design parameter level such as maximum displacements, accelerations and strains. Also frequency spectra are estimated reasonably well.

Key words: impact loaded reinforced concrete structure, vibration propagation, comparison of numerical analysis methods

Received 4 January 2018. Accepted 9 July 2018. Published online 16 August 2018.

\begin{abstract}
Earthquakes and aircraft impacts induce vibrations that propagate throughout the entire building and they need to be considered in designing SSCs (Structures, Systems and Components). Mainly linear calculation methods have been in use in design practice and the codes and standards consider damping ratios only for linear structural analyses. Induced vibrations, especially in damaged concrete structures, have not been studied extensively enough for optimization of structural frameworks and/or qualified systems and components. Experimental data on damping properties of damaged reinforced concrete are needed also for benchmarking analysis programs and methods.

Recently, within IMPACT project, a new type of test series considering vibration propagation has been carried out at VTT. The test target is a reinforced concrete structure with two parallel walls connected to a floor slab. The front wall is additionally supported
\end{abstract}

${ }^{1}$ Corresponding author: arja.saarenheimo@vtt.fi 
by triangular shaped side walls which are connected to the floor slab too. The test structure is lying on elastomeric bearing pads. Two steel pipes being effective mainly in compression act as horizontal support in the impact direction. Horizontal and vertical tension rods are attached to two steel beams located at the lower and upper edges of the front wall in order to prevent a horizontal movement opposite to the direction of the impact as well as a vertical lift-off, (see Figure 1). In order to obtain information on vibration propagation in damaged concrete structure at different levels of damage, the same structure was tested six times. At each time the mass of the deformable stainless steel missile was $50 \mathrm{~kg}$. The hit point is located in the middle of the front wall. The impact velocity was about $110 \mathrm{~m} / \mathrm{s}$ in the first four tests (V1A-D) and about $60 \mathrm{~m} / \mathrm{s}$ in the remaining two tests (V1E and F). In this paper, numerical results on tests $\mathrm{V} 1 \mathrm{~A}$ and $\mathrm{V} 1 \mathrm{~F}$ are compared with the corresponding experimental ones.

The calculated results, such as accelerations, displacements, their response spectra and strains, are compared with experimental measurements. Five finite element (FE) programs are used in computations: Abaqus, Europlexus, LS-DYNA, SOFiSTiK and an in-house code (IHC).

Most of the FE-codes in the present study use shell elements. In Abaqus and SOFiSTiK non-linear behaviour of shell section is modelled by dividing the cross section into layers. Reinforcements are also modelled as layers. In Europlexus and IHC, an alternative approach is adopted in which the non-linear behaviour of concrete and reinforcement is homogenized beforehand in the shell thickness direction obtaining relations between stress resultants and generalized strains valid for the shell section. In LS-DYNA, 3D solid elements for modelling concrete and beam elements for modelling reinforcements are used.

Equations of motion are integrated with explicit central difference time integration method, except in SOFiSTiK implicit integration method is used. Modelling and computations with the mentioned FE-programs are made independently of each other. Computations with LS-DYNA are carried out as blind exercises.

Interpretation of the results from the benchmarking point of view is still going on. However, it is clear that the computed results follow reasonably well the test results as far as the primary output values: displacements, accelerations and strains, are concerned. Also frequency spectra are estimated reasonably well.

\section{Introduction}

The primary task of protective walls is to keep possible impacting projectiles and burning fuel outside the building housing vulnerable equipment and protecting them against external loads. In addition, operability of sensitive equipment vital for plant safety may be lost due to heavy vibrations resulting from impact load. In this respect, validated analysis methods are needed in designing safety related structures and possible vibration isolation as well.

Vibration propagation test series $\mathrm{V}$, which is part of an experimental programme conducted at VTT concerning impact loaded concrete structures, was initiated with a test called V0, Ref. [1]. Test structure V0 was supported with a steel frame in a similar way as the slab specific tests earlier in related test series. Based on experience with V0 the 
next test structure V1 described here was designed so that the use of supporting frame could be avoided. In this way, damping effect would remain as much as practically possible in the V1 structure itself. The specimen rests on elastomeric bearing pads and it is additionally supported in horizontal and vertical directions.

Test series $\mathrm{V}$ was designed for studying the propagation of vibrations in concrete structures. The front wall is gradually damaged due to consecutive impacts. The floor and rear wall is subject to lower amounts of damage. This test therefore simulates the circumstances in rooms enveloped by massive reinforced concrete walls and floors, where protected SSCs are loaded by external vibrations from damaged structures.

Damping is an important factor influencing the response of structures during impact and especially when studying the propagation of vibrations in concrete structures. In the present study case viscous damping is assumed. Some guidelines for selecting damping values for reinforced concrete structure under different conditions can be found in literature. In Ref. [2], in Table 4, a damping value of $2 \%$ from the critical damping value (corresponding to damping ratio of 0.02 ) is given for concrete with slight cracking and with reinforcement below yield point. With considerable cracking the damping ratio increases to $0.03-0.05$. At yield point the damping ratio becomes still higher, about 0.07 0.1 and beyond yield point even higher. More recent studies on damping in concrete structures are reported e.g. in Refs [3] and [4].

The vibration propagation and damping test V1 is studied with several alternative models in order to find out how good agreement can be obtained with different independent analyses. Rayleigh damping model, Ref. [5], is used for simplicity. Finite Element (FE) codes Abaqus, Europlexus, LS-DYNA, SOFiSTiK and an in-house FE code (IHC) are used in numerical studies. Depending on the assumptions made by the analyst and the modelling features available in the computational codes, details of the calculation models vary. Different approaches are made to model the nonlinear support bearing behaviour and the loading transients. Also, the assumptions made for damping behaviour are different.

\section{Test}

The main purpose of test $\mathrm{V} 1$ is to study propagation and damping of vibration caused by impacts of deformable missiles. Reinforced concrete test structure is presented in Figure 1 with some main dimensions. The thickness of the front wall, triangular shaped side walls and floor slab is $0.15 \mathrm{~m}$ and the thickness of the rear wall is $0.25 \mathrm{~m}$. The width of the structure is $2.0 \mathrm{~m}$ and the span width of the front wall is $1.85 \mathrm{~m}$. There are $20 \mathrm{~mm}$ thick elastomeric bearings below the front wall and the rear wall. The vertical support system of the front wall is anchored to the basement with Dywidag bars of $40 \mathrm{~mm}$ diameter and with an effective length of about $2.9 \mathrm{~m}$. Short back pipes, with a length of about $1.1 \mathrm{~m}$, at the lower edge of the rear wall are connected to the base rock in order to prevent the horizontal displacement to the loading direction. Horizontally located Dywidag bars with a diameter of $32 \mathrm{~mm}$ and length of $3.7 \mathrm{~m}$ were utilised to prevent the movement of the target against the loading direction. These Dywidag bars are anchored to the base rock. 
The cylindrical compressive strength of concrete has been tested as $53.7 \mathrm{MPa}$ for the floor slab and 47.2 MPa for the walls. The main longitudinal (bending) reinforcement was made with $6 \mathrm{~mm}$ diameter rebars with a spacing of $50 \mathrm{~mm}$ and yield strength of $626 \mathrm{MPa}$. Stirrups of $6 \mathrm{~mm}$ diameter were arranged at a spacing of $100 \mathrm{~mm}$ in the impact area of the front wall.

The missile is shown in Figure 2. The main part is a stainless steel pipe with a wall thickness of $2 \mathrm{~mm}$. The wall thickness of the cap in the front of the missile is $3 \mathrm{~mm}$. A steel plate is added to the rear end of the missile in order to increase the total mass to 50 $\mathrm{kg}$. This type of missile has been used in many tests before and also with the same impact velocity. The structure was tested six times. The first four tests (V1A-D) were carried out with an almost identical impact to the same location, at the centre of front wall, with impact velocities of $113.6 \mathrm{~m} / \mathrm{s}, 114.9 \mathrm{~m} / \mathrm{s}, 114.7 \mathrm{~m} / \mathrm{s}$ and $112.6 \mathrm{~m} / \mathrm{s}$. The latter two tests (V1E and F) were carried out with somewhat lower impact velocities, $60.3 \mathrm{~m} / \mathrm{s}$ and 61.8 $\mathrm{m} / \mathrm{s}$, respectively. The deformed missiles after tests V1A and V1F are shown in Figure 3. The deformed length of the missile after the test V1A was $1280 \mathrm{~mm}$ and after the test V1F $1945 \mathrm{~mm}$, respectively.

All six tests were successful. By visual inspection, it could be seen that after each test especially the impact zone of the front wall was gradually slightly more and more damaged. Photographs of the impact area after the first and the last impact test are shown in Figure 4.

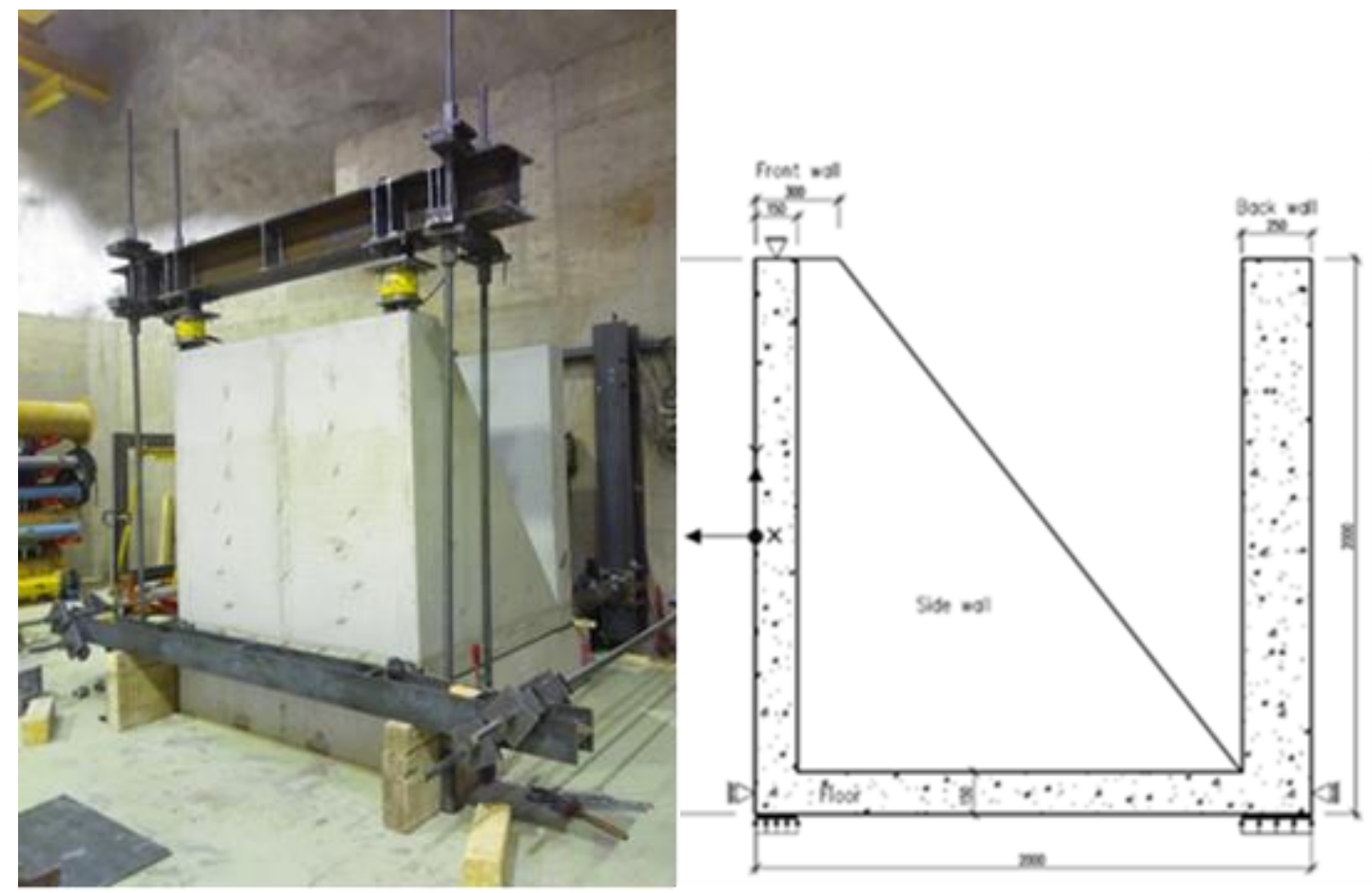

Figure 1. Reinforced concrete target with side view on the right hand side. 


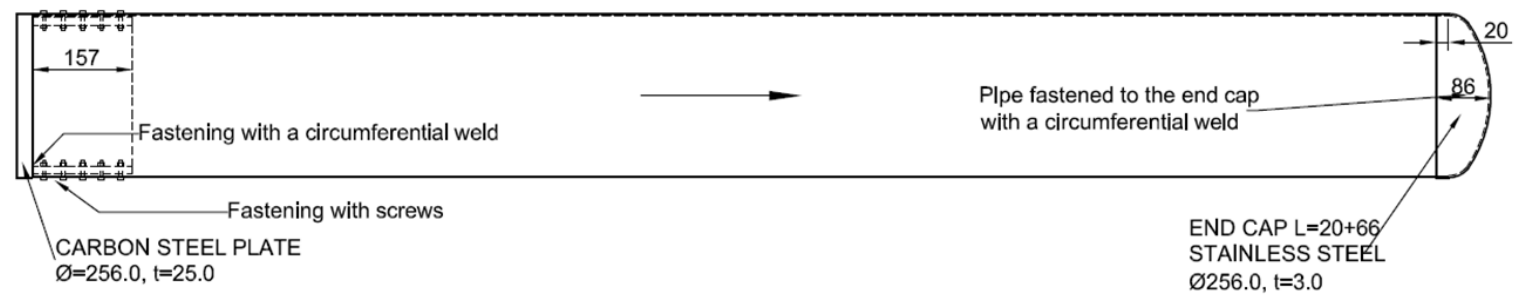

Figure 2. Stainless steel missile with a mass of $50 \mathrm{~kg}$.
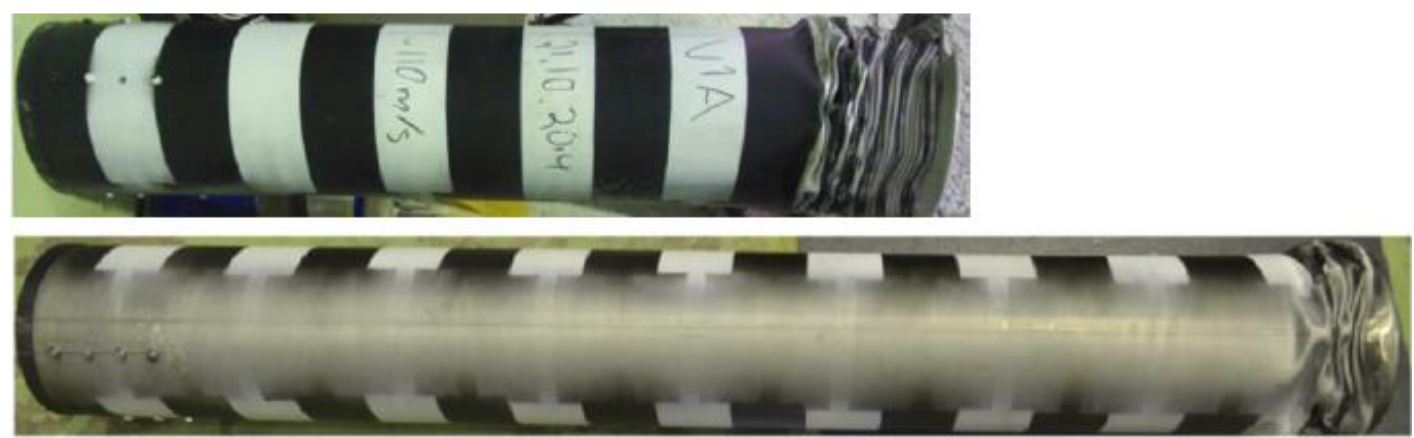

Figure 3. The deformed missile after test V1A and V1F.
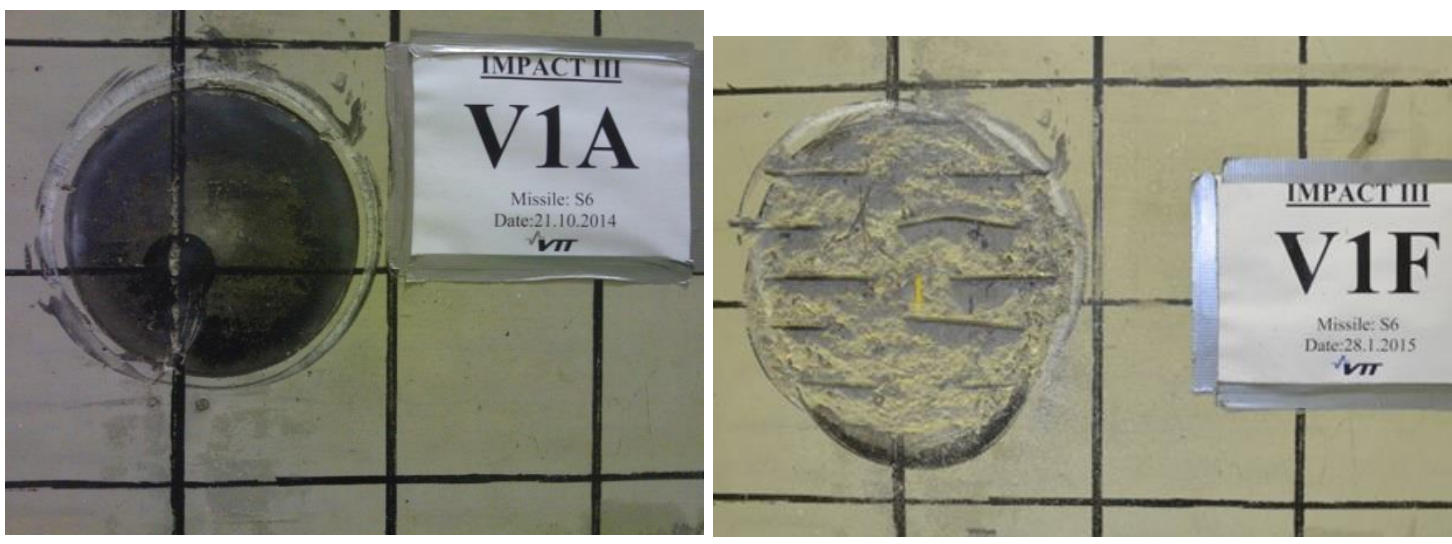

Figure 4. Damaged front surface of front wall after tests V1A and V1F.

\section{Finite element models}

Five finite element programs, Abaqus, Europlexus, an in-house code (IHC), LS-DYNA and SOFiSTiK, were used in computations. As an example two of the FE models are shown in Figure 5. 

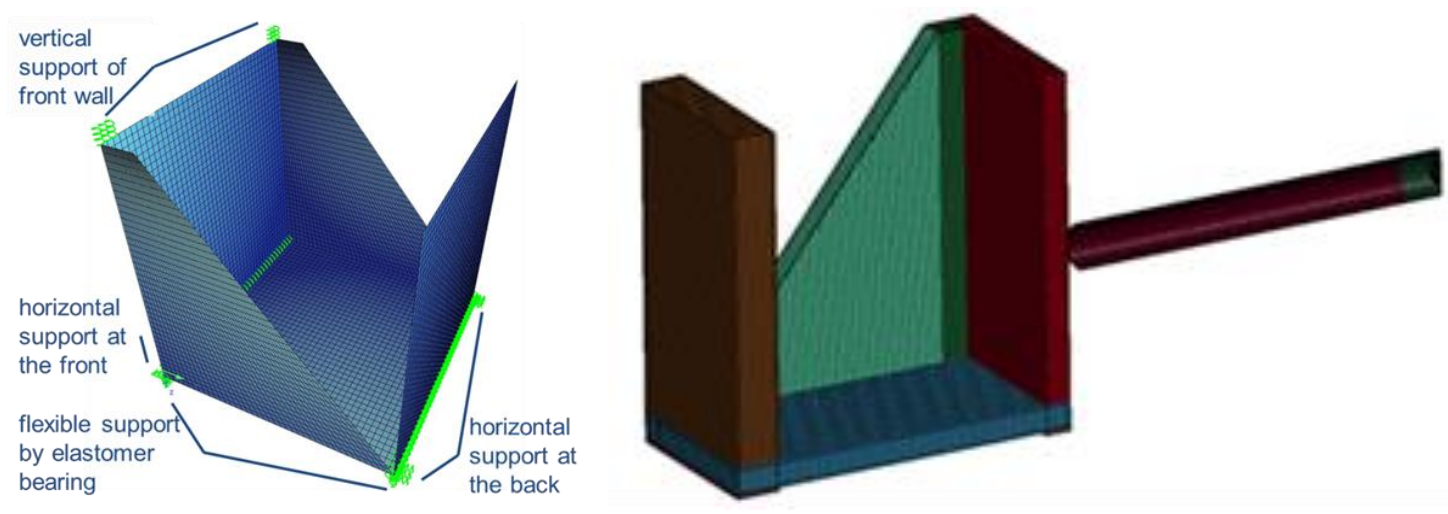

Figure 5. SOFiSTiK FE model with supports on the left and LS-DYNA model on the right.

\section{Abaqus/Explicit model}

In Abaqus/Explicit, Ref. [6], model, the FE mesh consists of bilinear four-noded shell elements with reduced integration and 11 section points through the thickness. Nonlinear transverse shear behaviour is not taken into consideration. The concrete obeys to the Concrete Damaged Plasticity material model which includes tension softening and a damage (stiffness degradation) evolution both in compression and tension. The reinforcement is modelled as layers. An elastic plastic material model with von Mises yield surface and isotropic yield hardening is applied for reinforcement steel. Elastomeric pads, Dywidag bars and back pipes are modelled with spring elements. The assumed Rayleigh damping ratio is 0.05 at frequencies 45 and $5000 \mathrm{~Hz}$.

Gravity load is imposed during the first analysis step. Impact force time function, or more precisely the pressure time history when accounting for the load distribution area are applied as loads to simulate the missile impact in all the consecutive analyses steps simulating the tests V1 A-F. In the following for simplicity the term impact force time function is used.

\section{Europlexus model}

This model deals with damage and plasticity mechanisms and takes into account both membrane and bending behaviour of the orthotropic shell-type structural elements for monotonic or cyclic loading, Ref. [7]. Thick shell elements are used with full integration. The GLRC DAMA (GLobal Reinforced Concrete with DAMAge) stress-resultant constitutive law is based on the homogenization of the non-linear behaviour of concrete and steel in the RC section, Ref. [7]. It is formulated in terms of generalized stresses and strains (membrane force, bending moment, transverse shear stress, membrane strain, curvature, transverse shear strain). In Europlexus code a complete interaction between the stress resultants is taken into consideration.

Elastomeric pads, Dywidag bars and back pipes are modelled with spring elements. Damping is modelled here in more detail than in the other analyses. It is calibrated for each structural element based on the modal analysis of the mock-up. The upper bound of 
the Rayleigh damping frequency range is chosen as the frequency for which $90 \%$ of the total mass is involved. The lower bound is approximately the first eigenfrequency of each structural element.

The damping coefficient for the elastomer is calculated from the compressive stiffness: $A_{l}=\beta K_{l}$ with $\beta=D /(\pi f)$, where the degree of damping $D=0.08$ or $8 \%$ and the natural frequency of elastomer bearing $f$ is roughly $25 \mathrm{~Hz}$ according to the supplier website. $K_{l}$ is the stiffness in question. Therefore damping $A_{l}$ is roughly equal to $K_{l} / 1000$. The supporting system is also modelled with linear spring elements, described in the following. In addition to compression stiffness, shear stiffness of the pads is also taken in account in this model.

One calculation is performed: First the V1A impact is analysed at $110 \mathrm{~m} / \mathrm{s}$ and then the V1F impact at $60 \mathrm{~m} / \mathrm{s}$. This has not a large effect on $\mathrm{V} 1 \mathrm{~F}$ results as strains are quite small at the end of the first impact. Gravity load is imposed at the beginning of the calculation. Displacements are stabilised before each impact phase through a quasi-static damping phase.

\section{In-house code (IHC) model}

A 24-degree-of-freedom (24 DOF) flat shell element is used in the computations of the vibration test. The element is constructed by combining a plate element and a membrane element and using a coordinate transformation from local to global coordinate system. The degrees of freedom of the shell element in local frame are: $u, v, w, \theta_{x}, \theta_{y}$ and $\theta_{z}(3$ translations and 3 rotations). The rotation corresponding to the local rotation $\theta_{z}$ is restrained except at shell junctions where two elements meet at an angle different from $\pi$.

The plate part of the element is constructed according to the Reissner-Mindlin theory. Bilinear polynomial interpolation is used for the deflection and the rotations. In computing the transverse shear strains covariant transverse shear strain assumption and interpolation is adopted, Ref. [8]. The von Karman definition of nonlinear Lagrangian strain is used in computing the membrane strains. Material nonlinearities are formulated in terms of stress resultants and curvatures in a similar fashion as e.g. in Refs. [9] and [10]. Interaction between the bending resultants is taken into account. In reverse motion, cracked state stiffness is assumed. Yield condition is defined in terms of strains and stress resultants. Separate yield condition is used for transverse shear forces.

The elastomeric pads under the walls are modelled with lines of spring elements beneath the walls corresponding to a stiffness $k=100 \mathrm{MN} / \mathrm{m}^{3}$ (estimated from Figure 6), effective only in compression. Dywidag bars and back pipes are also modelled with spring elements. Masses of supporting system are added to the computational model. For HEB300 $m=117 \mathrm{~kg} / \mathrm{m}$. The mass of the supporting system above front wall becomes about $400 \mathrm{~kg}$.

The assumed Rayleigh damping ratio is 0.05 at frequencies 45 and $1000 \mathrm{~Hz}$. Gravity load is imposed during the first analysis phase. Impact force time functions are applied for impact loads in all the consecutive analyses steps simulating the tests V1 A-F. 


\section{LS-DYNA model}

A full three dimensional model including the impacting projectile is developed. The projectile is modelled using shell elements. The reinforced concrete slab is represented by eight-noded solid elements for concrete, beam elements for reinforcement as well as stirrups for shear. Material model 159 for concrete is adopted, Ref. [11]. Supports are modelled as fixed. The elastomeric bearing pads are modelled using solid elements where the movement of their outer nodal points is restrained in the vertical direction and an elastic material model based on the initial modulus of elasticity of the $20 \mathrm{~mm}$ thick bearing, adapted from the compression stress diagram shown in Figure 6, is used. Contact surfaces are defined between the projectile and the concrete wall, as well as between the concrete floor slab and its supporting bearings.

In support areas horizontal and vertical displacements are restrained. Symmetrical arrangements have been taken into consideration, where only half of the test body and the impacting missile are modelled.

The initial position of the impacting projectile is defined on the surface of the concrete front wall. The impacting projectile is then subjected to a pre-defined initial velocity. At the same time the rest of the model is subjected to acceleration due to gravity, in order to account for self-weight of the structure.

The damping is mainly accounted for by the material energy dissipation. A low additional Rayleigh damping of $1 \%$ is considered in this model. The numerical analyses here do not take into consideration the effect of consecutive impacts on the wall.

LS-DYNA and the above mentioned programs use explicit central difference time integration method.

\section{SOFISTiK model}

The numerical methods of the utilized computer program Ref. [12], include the consideration of the effects caused by non-linear material behaviour of the shell structures and the investigation of 2nd and 3rd order theory effects due to geometrically non-linear behaviour. The non-linear behaviour of the components of reinforced concrete is defined by uniaxial stress-strain law of concrete (biaxial behaviour regarded), consideration of tension stiffening and tension softening, transverse shear deformations approximately included by an elastic/ideally plastic shear stress/shear strain law after exceeding specified ultimate shear strength and trilinear stress-strain laws of reinforcing steel.

The mass of the upper vertical support system of the front wall is assumed as $400 \mathrm{~kg}$.

Parametric analyses were carried out in order to investigate the influence of the boundary conditions on the displacements with special focus on the lift-off of the test structure from the rear elastomer bearing. The obtained results show that additional vertical forces can be transferred at the horizontal supports due to unintended friction. These forces contribute to a significant decrease of the vertical displacements and accelerations of the rear wall.

Analysis results with best simulation of the measured mechanical behaviour of the specimen are achieved with a coefficient of friction $\mathrm{COF}=0.3$ and a small unscheduled prestressing of the Dywidag bars of $10 \mathrm{kN}$. 
The analyses have been performed for all tests V1A until V1F by taking into account the prior damage due to the preceding tests. Equations of motion are integrated with an implicit time integration method.

\section{Comparison of calculation models}

The main characteristics of the five different finite element models are compiled in Table 1 .

Table 1. Main characteristics of FE models.

\begin{tabular}{|c|c|c|c|c|c|}
\hline Code & Element type & $\begin{array}{c}\text { Element } \\
\text { size } \\
(\mathrm{mm})\end{array}$ & $\begin{array}{c}\text { Concrete } \\
\text { material } \\
\text { model }\end{array}$ & Load & Damping \\
\hline $\begin{array}{l}\text { Abaqus } \\
\text { Explicit }\end{array}$ & $\begin{array}{l}\text { Shell, rebar as } \\
\text { layers }\end{array}$ & 50 & $\begin{array}{l}\text { Concrete } \\
\text { damaged } \\
\text { plasticity }\end{array}$ & $\begin{array}{l}\text { Force-time } \\
\text { function } \\
\text { Gravity }\end{array}$ & $\begin{array}{l}\text { Rayleigh: } \\
5 \% \text { at } 45 \mathrm{~Hz} \text { and } \\
5000 \mathrm{~Hz}\end{array}$ \\
\hline $\begin{array}{l}\text { Europlexus } \\
\text { Explicit }\end{array}$ & $\begin{array}{l}\text { Reissner- } \\
\text { Mindlin shell }\end{array}$ & 40 & $\begin{array}{l}\text { Front and } \\
\text { side walls: } \\
\text { Non-linear } \\
\text { moment- } \\
\text { curvature } \\
\text { GLRC } \\
\text { DAMA }\end{array}$ & $\begin{array}{l}\text { Force-time } \\
\text { function } \\
\text { Gravity }\end{array}$ & $\begin{array}{l}\text { Rayleigh: } \\
4 \% \text { at } 220 \mathrm{~Hz}, \\
7 \% \text { at } 45 \mathrm{~Hz} \\
\text { (Front wall) } 12 \\
\mathrm{~Hz} \text { (Rear wall) } \\
20 \mathrm{~Hz} \text { (Side } \\
\text { walls, floor) }\end{array}$ \\
\hline $\begin{array}{l}\text { IHC } \\
\text { Explicit }\end{array}$ & $\begin{array}{l}\text { Reissner- } \\
\text { Mindlin shell }\end{array}$ & 120 & $\begin{array}{l}\text { Non-linear } \\
\text { moment- } \\
\text { curvature }\end{array}$ & $\begin{array}{l}\text { Force-time } \\
\text { function } \\
\text { Gravity }\end{array}$ & $\begin{array}{l}\text { Rayleigh: } \\
5 \% \text { at } 45 \mathrm{~Hz} \text { and } \\
1000 \mathrm{~Hz}\end{array}$ \\
\hline $\begin{array}{l}\text { LS-DYNA } \\
\text { Explicit }\end{array}$ & $\begin{array}{l}\text { concrete: solid } \\
\text { rebar \& } \\
\text { stirrups: beam }\end{array}$ & $\begin{array}{l}25 * 25 \\
* 25\end{array}$ & $\begin{array}{l}\text { Surface cap } \\
\text { Mat } 159\end{array}$ & $\begin{array}{l}\text { Missile } \\
\text { modelled: } \\
\text { shell } \\
\text { elements }\end{array}$ & Rayleigh: $1 \%$ \\
\hline $\begin{array}{l}\text { SOFiSTiK } \\
\text { Implicit }\end{array}$ & $\begin{array}{l}\text { Shell, layer } \\
\text { model of } \\
\text { reinforced } \\
\text { concrete } \\
\text { section }\end{array}$ & 50 & $\begin{array}{l}\text { Nonlinear } \\
\text { stress-strain } \\
\text { law }\end{array}$ & $\begin{array}{l}\text { Force-time } \\
\text { function }\end{array}$ & $\begin{array}{l}\text { Rayleigh: } 1 \% \text { for } \\
\text { front wall, } 2 \% \\
\text { for other walls } \\
\text { and floor }\end{array}$ \\
\hline
\end{tabular}




\section{Support modelling}

The supports are mainly modelled with linear or nonlinear spring elements.

\section{Vertical supports}

Stiffness of the elastomer bearing pad can be distributed to the springs located at the nodal points below the front and rear walls. Mechanical properties for the $20 \mathrm{~mm}$ thick elastomer are available on the supplier website Ref. [13] and shown in Figure 6. Compressive stiffness can be calculated taking into account the width of each elastomer row in loading direction, which is $15 \mathrm{~cm}$ below the front wall, and $25 \mathrm{~cm}$ below the rear wall. Shear stiffness $K_{t}$ can be deduced from the compressive ones.

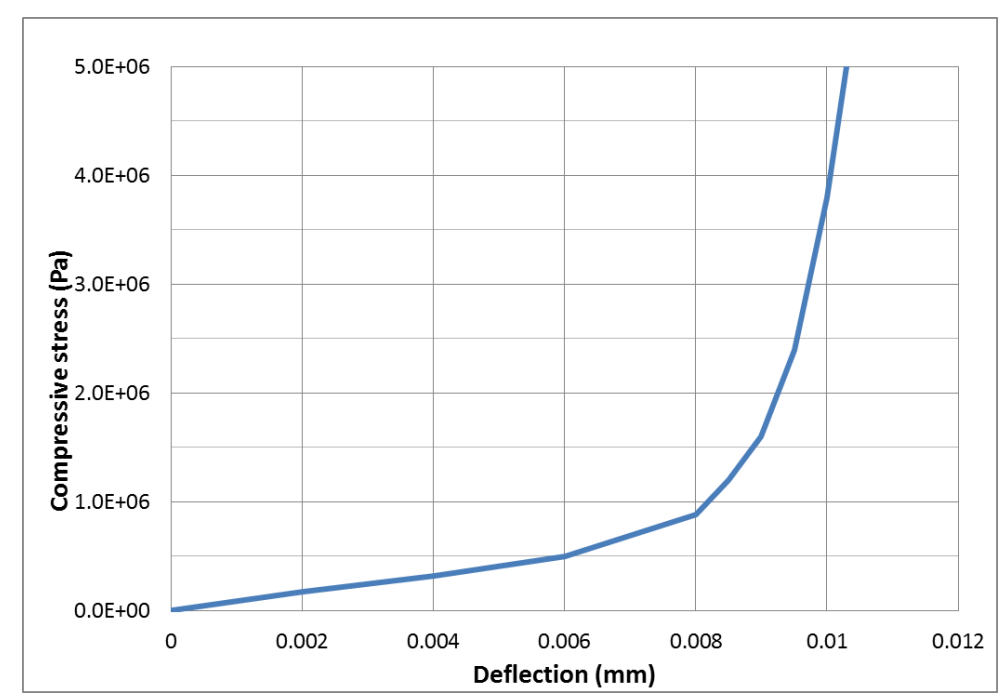

Figure 6. Deflection of Calenberg bi-Trapez Bearings ${ }^{\circledR}, \mathrm{t}=20 \mathrm{~mm}$.

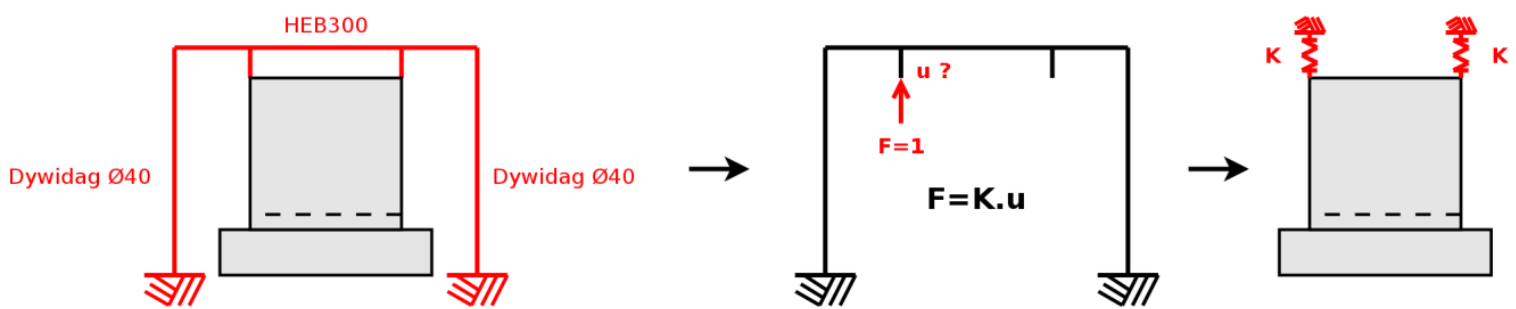

Figure 7. Simplified models for support stiffnesses.

The vertical support system at the upper edge of the front wall (see Figure 1) consists of four Dywidag bars with a diameter of $40 \mathrm{~mm}$ (two bars at each side). These vertical bars are connected to a horizontal I-section beam, HEB300. The lower ends of the bars are anchored to the base rock. Stiffness behaviour of this structure can be modelled with two springs. The stiffness of the spring can be calculated using a simple model of the 
Dywidag bars and the I-section beam (see Figure 7). The obtained stiffness mainly depends on the length and cross-sectional area of the Dywidag bar. It is worth to notify that it barely depends on the distance from the supports since the I-beam is much stiffer than the Dywidag bars.

\section{Horizontal supports}

The displacements of the mock-up against the loading direction are restricted by four Dywidag bars (two bars at each side) with a diameter of $32 \mathrm{~mm}$. These bars are connected to an I-beam, HEB180, at the front of the mock-up and anchored to the base rock at the other end. This horizontally acting support system is shown in Figure 1.

The stiffness of this horizontal support system can be calculated by applying a similar simplified model as presented in Figure 7. In this case the stiffness of the Ibeam, HEB 180, clearly affects the spring stiffness.

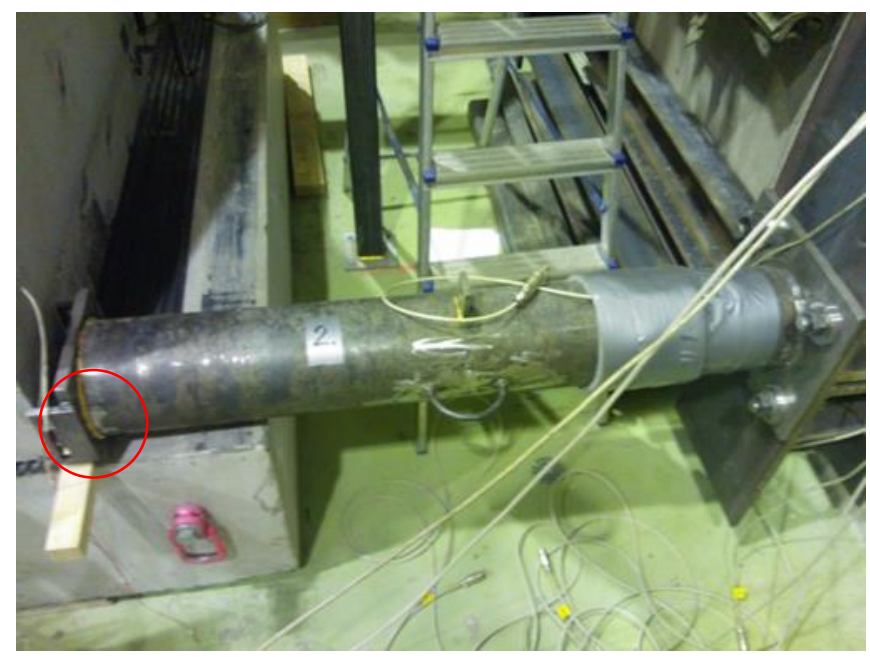

Figure 8. Horizontal back pipe.

Horizontal back pipes shown in Figure 8 at the lower corners of the rear wall prevent the displacements to the loading direction. The axial stiffness of the horizontal back pipe can be simply calculated as $k=E A / L$, using the length $L$ and the cross-sectional area $A$ of the back pipe and the modulus of elasticity $E$. The outer diameter of the pipe is 168.3 $\mathrm{mm}$, wall thickness is $12.5 \mathrm{~mm}$ and the length of the pipe is $1067 \mathrm{~mm}$.

When considering the measured vertical displacement histories of the rear wall, it can be concluded that these horizontal pipes do provide some support actions also to the vertical direction. It may be related to the rolling cylinder used as a low area contact surface between the back wall and both back pipes (this cylinder is highlighted with a red circle in Figure 8).

\section{Comparison of support modelling}

Based on the available information on the support structures and their material properties, slightly different types of assumptions were made. Mechanical properties 
(tension/compression stiffness unless "shear" is mentioned) applied for support modelling are summarized in Table 2.

Table 2. Support modelling.

\begin{tabular}{|c|c|c|c|c|c|}
\hline Code & $\begin{array}{l}\text { Front wall, } \\
\text { lower edge } \\
\text { horizontal* } \\
{[\mathrm{MN} / \mathrm{m}]}\end{array}$ & $\begin{array}{l}\text { Front wall, } \\
\text { lower edge } \\
\text { vertical } \\
{[\mathrm{MN} / \mathrm{m}]}\end{array}$ & $\begin{array}{l}\text { Front wall, } \\
\text { upper edge } \\
\text { vertical* } \\
{[\mathrm{MN} / \mathrm{m}]}\end{array}$ & $\begin{array}{l}\text { Rear wall, } \\
\text { lower edge } \\
\text { horizontal* } \\
{[\mathrm{MN} / \mathrm{m}]}\end{array}$ & $\begin{array}{l}\text { Rear wall, } \\
\text { lower edge } \\
\text { vertical } \\
{[\mathrm{MN} / \mathrm{m}]}\end{array}$ \\
\hline Abaqus & $\begin{array}{l}91.3 \\
\text { (against } \\
\text { loading } \\
\text { direction) }\end{array}$ & $\begin{array}{l}32.25 \\
\text { (downwards } \\
\text { only) }\end{array}$ & $\begin{array}{l}129 \\
\text { (upwards } \\
\text { only) }\end{array}$ & $\begin{array}{l}1204 \\
\text { (loading } \\
\text { direction)** }\end{array}$ & $\begin{array}{l}53.7 \\
\text { (downwards } \\
\text { only) }\end{array}$ \\
\hline Europlexus & $\begin{array}{l}91.2 \\
\text { (against } \\
\text { loading } \\
\text { direction) }\end{array}$ & $\begin{array}{l}\text { 26.6, Shear } \\
1.32 \\
\text { Damping } \\
0.0306 \\
\text { MN.s/m } \\
\text { (downwards } \\
\text { only) }\end{array}$ & $\begin{array}{l}134.5 \\
\text { (upwards } \\
\text { only) }\end{array}$ & $\begin{array}{l}1201 \\
\text { (loading } \\
\text { direction) }\end{array}$ & $\begin{array}{l}74.1, \\
\text { Shear } 2.2 \\
\text { Damping } \\
0.0853 \\
\text { MN.s/m } \\
\text { (downwards } \\
\text { only) }\end{array}$ \\
\hline IHC & $\begin{array}{l}91.2 \\
\text { (against } \\
\text { loading } \\
\text { direction) }\end{array}$ & $\begin{array}{l}30 \\
\text { (downwards } \\
\text { only) }\end{array}$ & $\begin{array}{l}117.5 \\
\text { (upwards } \\
\text { only) }\end{array}$ & $\begin{array}{l}1204 \\
\text { (loading } \\
\text { direction) }\end{array}$ & $\begin{array}{l}50 \\
\text { (downwards } \\
\text { only) }\end{array}$ \\
\hline LS-DYNA & Fixed nodes & $\begin{array}{l}\text { Elastomeric } \\
\text { pads modelled: } \\
\text { solid el. E=2.5 } \\
\mathrm{MPa}\end{array}$ & $\begin{array}{l}\text { Fixed } \\
\text { nodes }\end{array}$ & Fixed nodes & $\begin{array}{l}\text { Elastomeric } \\
\text { pads } \\
\text { modelled: } \\
\text { solid el. } \\
\mathrm{E}=2.5 \mathrm{MPa}\end{array}$ \\
\hline SOFiSTiK & $\begin{array}{l}11 \\
\text { (against } \\
\text { loading } \\
\text { direction) }\end{array}$ & $\begin{array}{l}33.75 \\
\text { (downwards } \\
\text { only) } \\
\text { Damping 8\% }\end{array}$ & $\begin{array}{l}120 \\
\text { (upwards } \\
\text { only) }\end{array}$ & $\begin{array}{l}1071 \\
\text { (loading } \\
\text { direction) }\end{array}$ & $\begin{array}{l}56.25 \\
\text { (downwards } \\
\text { only)*** } \\
\text { Damping 8\% }\end{array}$ \\
\hline
\end{tabular}

\footnotetext{
*at one corner

**additional vertical stiffness for back pipes downwards $48 \mathrm{MN} / \mathrm{m}$ upwards $12 \mathrm{MN} / \mathrm{m}$

$* * *$ Friction coefficient $=0.3$ transverse to rear horizontal support
} 


\section{Loading}

The impact load is given either by assigning a uniformly distributed transient pressure load on impact area or by simulating the missile and its impact explicitly (LS-DYNA). The impact load time histories obtained from LS-DYNA, in Figure 9, are the unfiltered contact forces between the projectile and the target slab.

Pressure load is obtained by distributing the analytically calculated force-time function on the assumed loading area. Force-time functions are calculated by using the Riera formula Ref. [14], where the impact force is a sum of the mass flow and the crushing forces of the missile. In this case, the crushing force of the missile is considerably higher than the force due to the mass flow. The discrepancies between the different analytically calculated loading functions are mainly due to the different assumptions made for the crushing force of the missile. The short lived force peak in the beginning of the loading function is due to the impact of the $3 \mathrm{~mm}$ thick front cap.

Impact forces as a function of time used in different analyses are presented in Figure 9. The impact durations measured during experiment were $0.019 \mathrm{~s}$ and $0.013 \mathrm{~s}$ for test V1A and V1F, respectively.
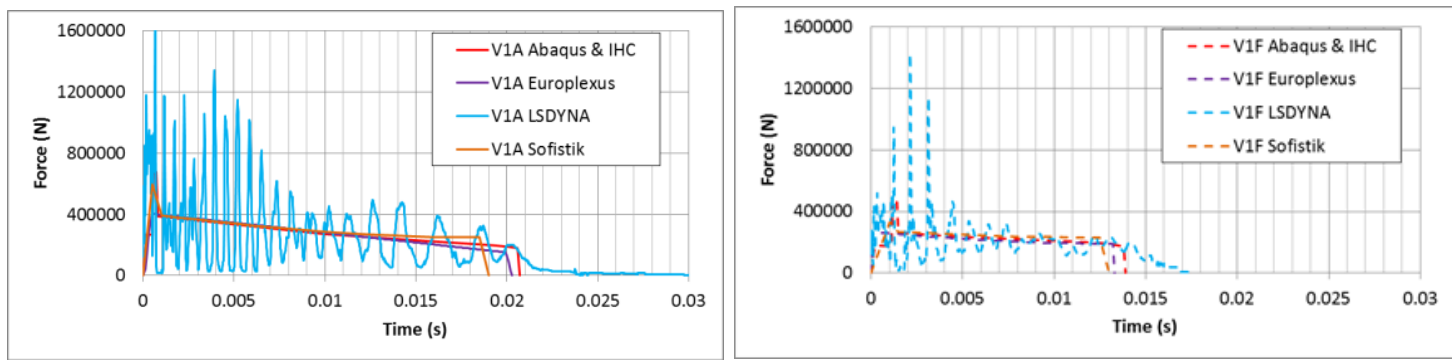

Figure 9. Impact force as a function of time calculated with the Riera method and FEM (Missile contact/impact analysis) Left: V1A simulations. Right: V1F simulations.

\section{Calculation results on V1A Test}

\section{Displacements}

Figure 10 shows the calculated and measured displacements at the centre of front slab as a function of time. The horizontal displacement is considered to be negative in the loading direction. The black curve represents always the measured values. The maximum deflection and the permanent deflection are predicted quite accurately by all the models. The somewhat higher displacement value obtained by Europlexus computation may be partly due to slightly too wide front wall in the model. In reality the span width is $1.85 \mathrm{~m}$ and in this model it is $2.0 \mathrm{~m}$. Horizontal displacements at the top of the rear wall centre are presented in Figure 11. Bending vibration behaviour of the rear wall calculated by IHC agree quite well with the corresponding measurement result.

Vertical displacements of the rear wall are shown in Figure 12. The vertical displacement is positive to the upwards direction. Vertical displacements obtained by Abaqus and SOFiSTiK codes are rather similar due to the assumptions regarding the vertical support. In modelling these supports, also assumptions due to the friction between 
the wall and horizontal back pipes were taken into consideration. In other models this vertical support assumption was not made and the structure is moving upwards.

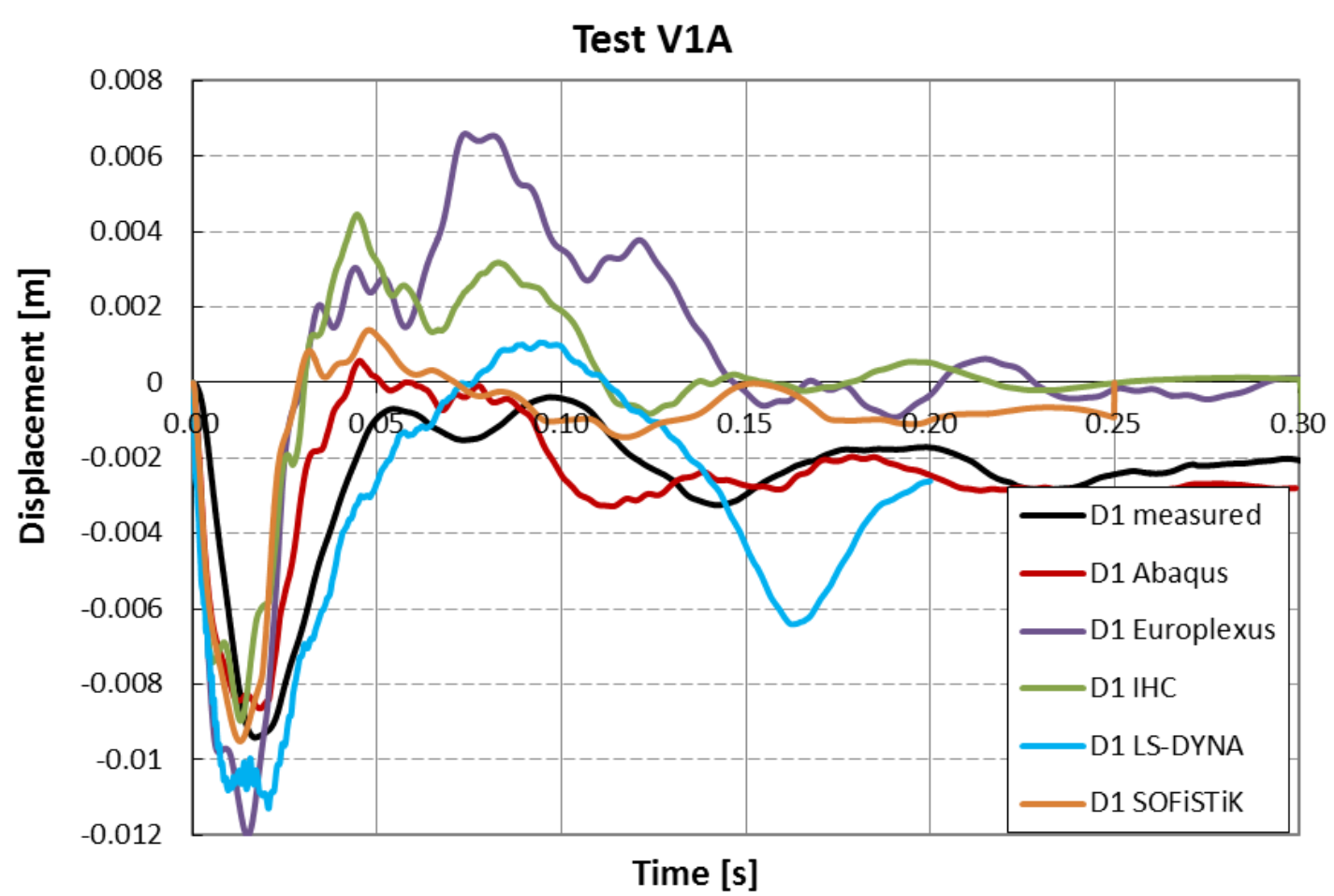

Figure 10. Horizontal displacement at the centre of the front wall in the impact direction.

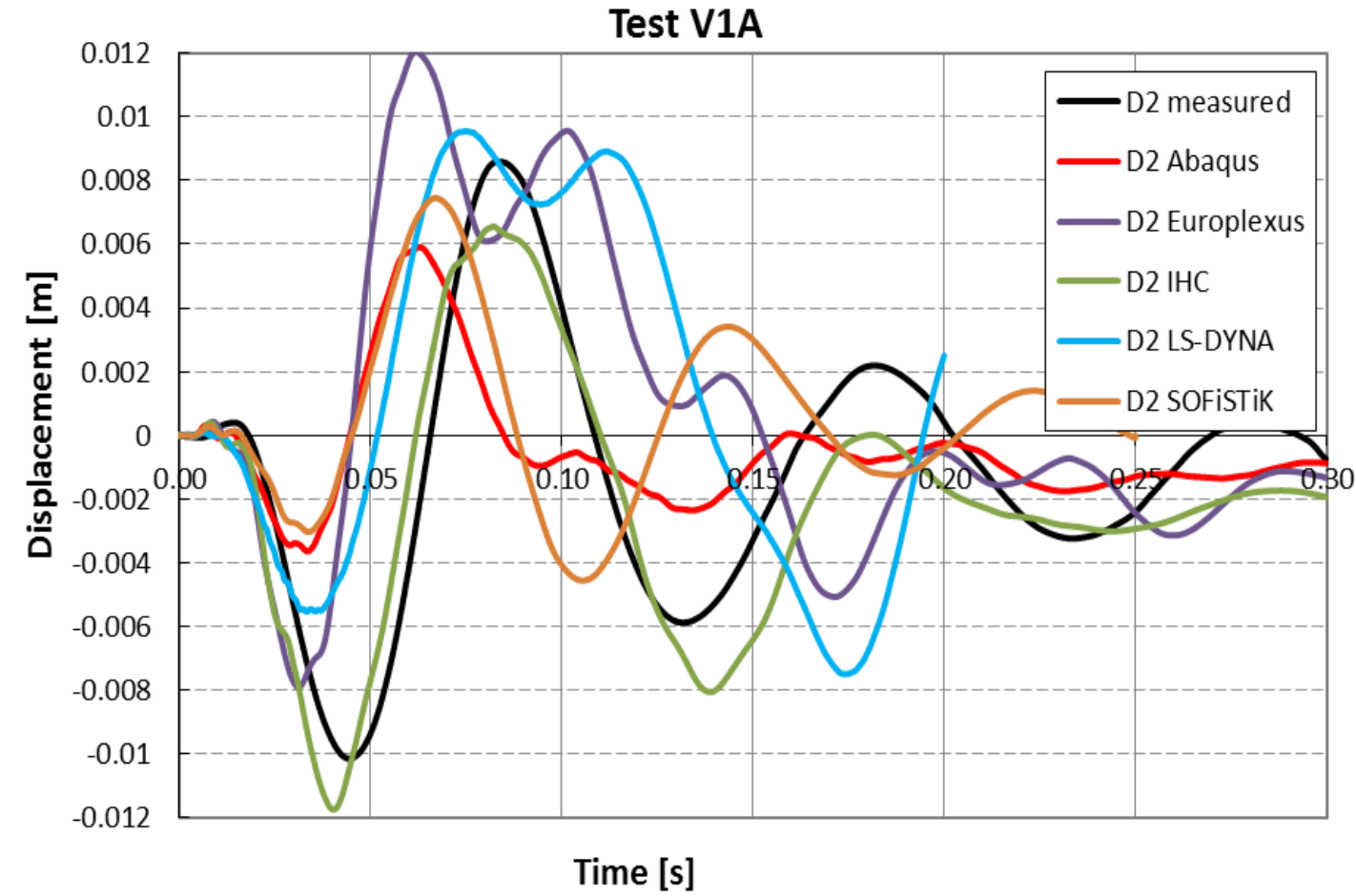

Figure 11. Horizontal displacement at the top of the rear wall in the impact direction. 


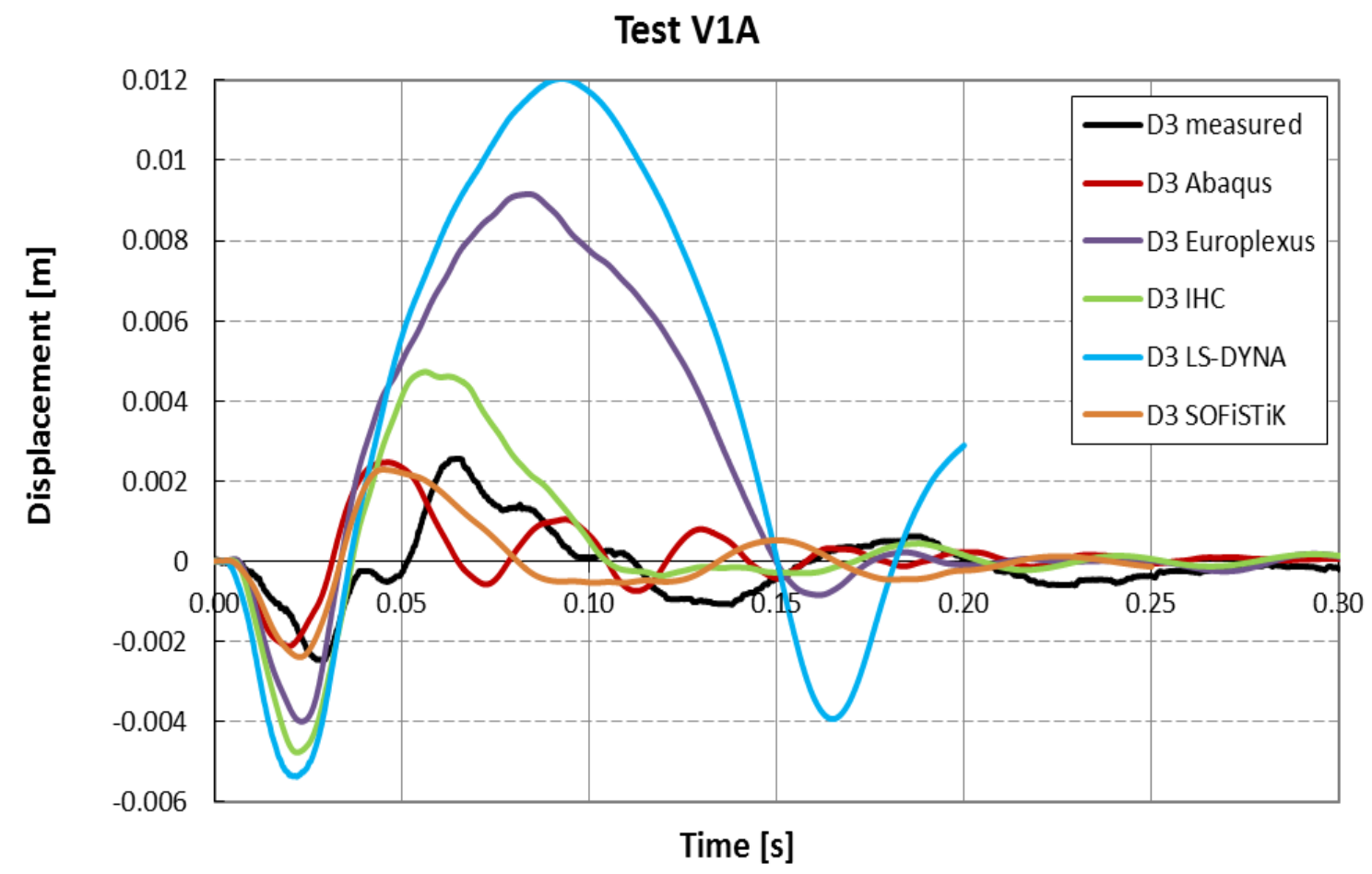

Figure 12. Vertical displacement of the rear wall.

\section{Strain in reinforcement}

The measured and calculated strains in the centre of the front wall, at the impact location, in the back surface vertical reinforcement are shown in Figure 13 and corresponding results on horizontal back surface reinforcement are shown in Figure 14.

The structure is behaving rather linearly. Some plastic yielding occurs in the bending reinforcement at the impact area. According to the calculated results obtained with Abaqus, LSDYNA and SOFiSTiK codes, strains in the horizontal direction are higher than in the vertical direction. However, horizontal maximum strains calculated with IHC and Europlexus codes are lower than the corresponding vertical strain values and they are also in a rather good agreement with the measured result. In these two codes non-linear moment-curvature relationship is applied for modelling bending behaviour. 


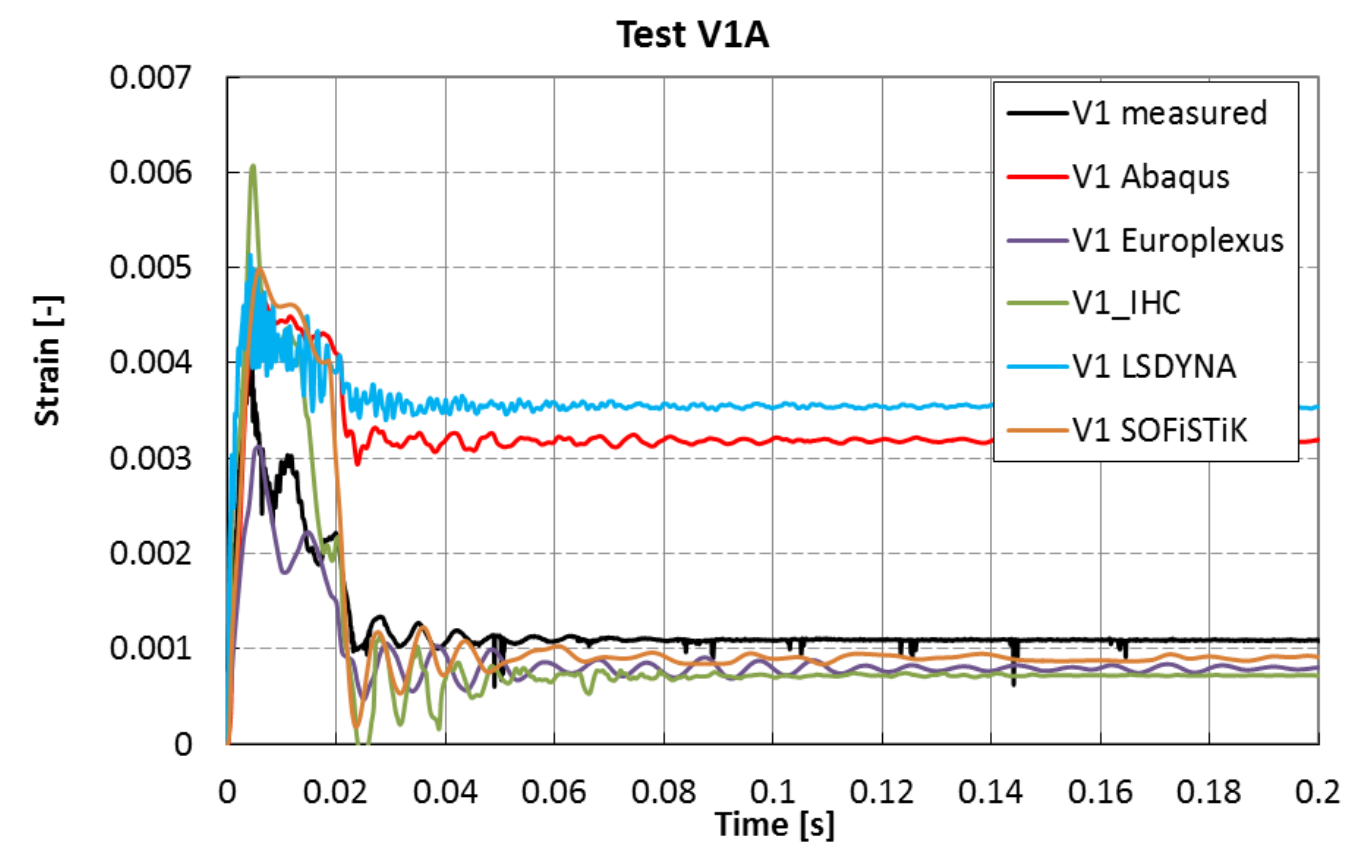

Figure 13. Strain at the vertical back surface reinforcement of the front wall.

Test V1A

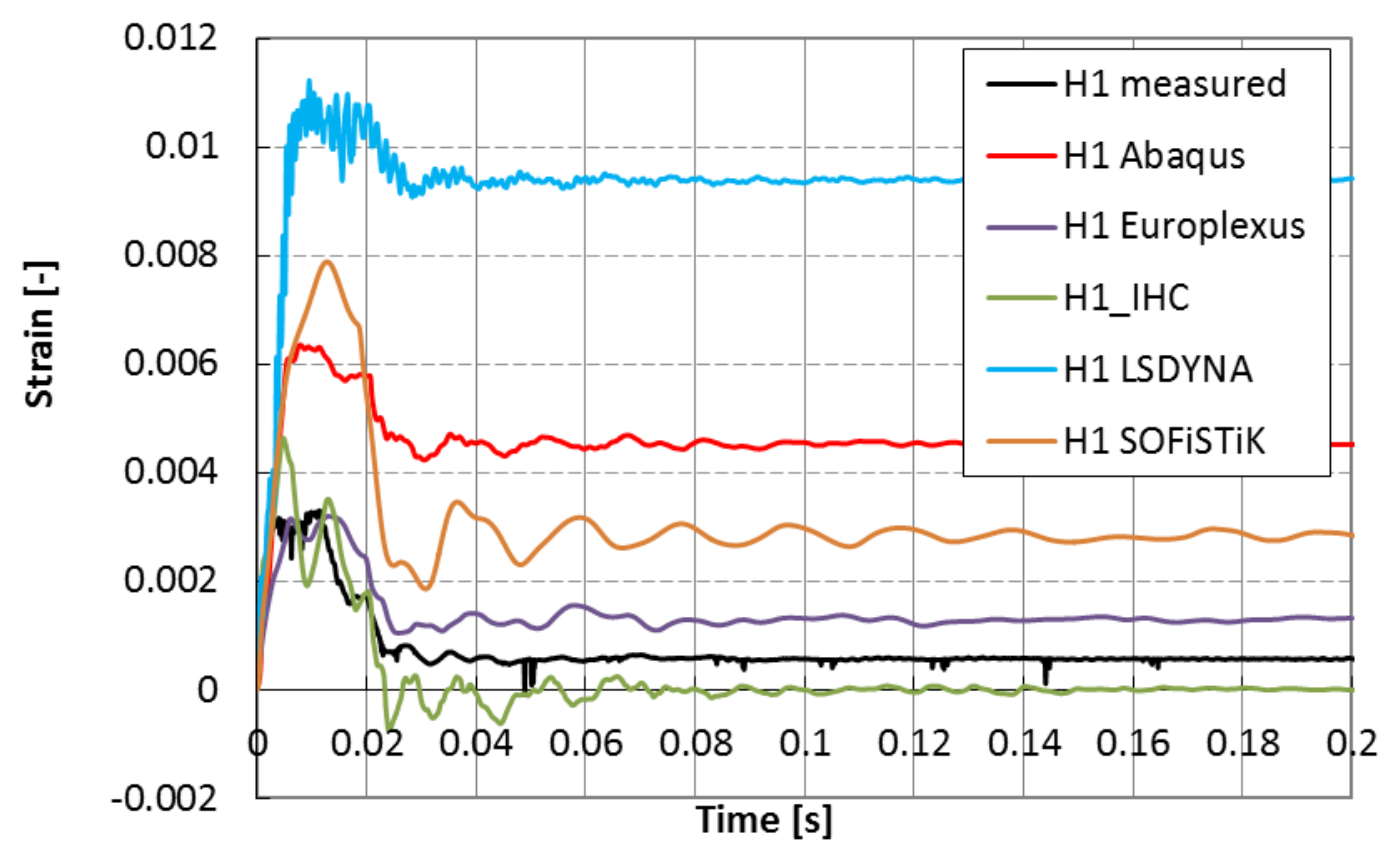

Figure 14. Strain at the horizontal back surface reinforcement of the front wall. 


\section{Response spectra}

Floor response spectra are computed from the measured and calculated acceleration results adopting a 5\% damping. For the measured acceleration spectra the filtered values less than $250 \mathrm{~Hz}$ are applied. Calculated displacement and acceleration spectra are compared with the corresponding measured values. Floor response spectra are calculated from nonfiltered accelerations. Acceleration spectra results obtained at location 5, at the top of the rear wall centre, are presented in Figure 15a and the corresponding displacement spectra results are shown in Figure 15b. According to the measurements, the displacement response spectra at frequency values higher than $100 \mathrm{~Hz}$ are below 2 $\mathrm{mm}$ during Test V1A. A similar result is obtained with most of the calculation models too. Thus, acceleration spectra only at the frequency range below $100 \mathrm{~Hz}$ are considered. Acceleration spectra results obtained at location 3, at the junction of the rear wall and floor, are presented in Figure 16a and the corresponding displacement spectra results are shown in Figure 16b.
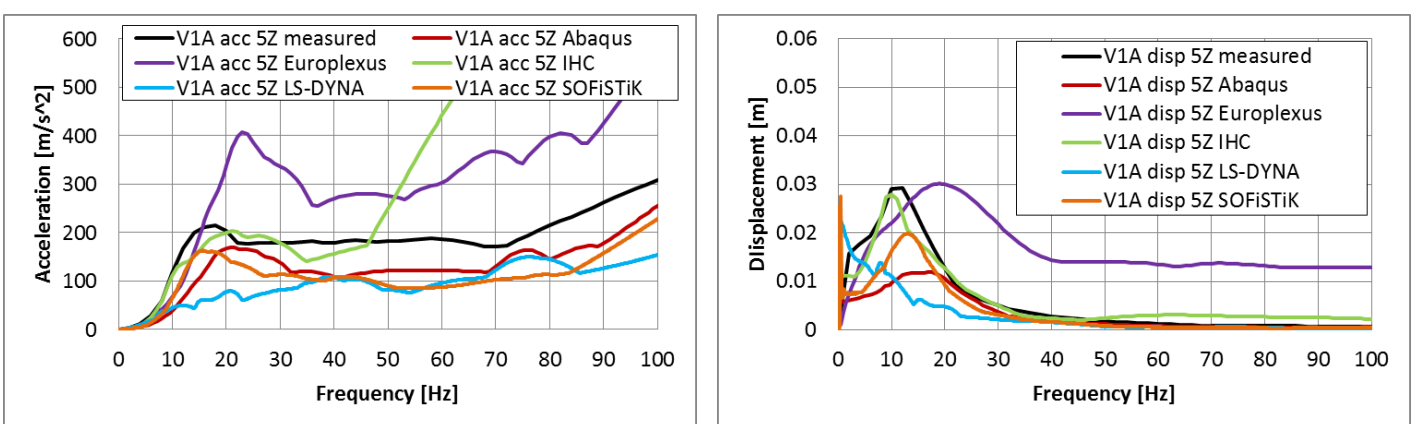

Figure 15. a) Acceleration spectra and b) displacement spectra at the top of the rear wall, horizontal direction .
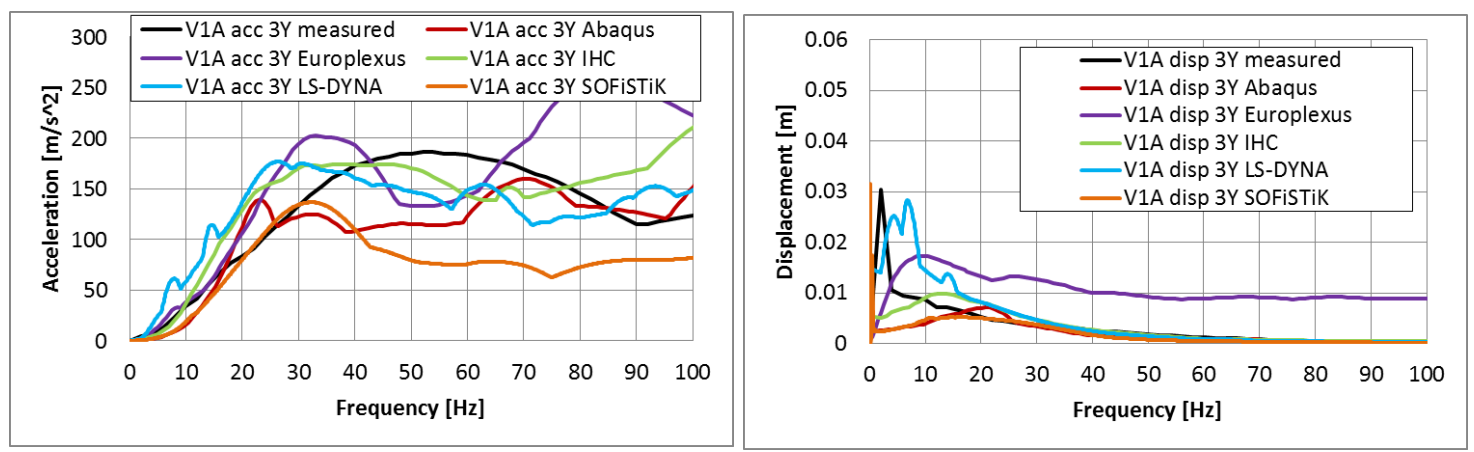

Figure 16. a) Acceleration spectra and b) displacement spectra at the lower edge of the rear wall, vertical direction. 


\section{Calculation results on V1F Test}

\section{Displacements}

All the measured and calculated values presented here start from zero. Figure 17 shows the calculated and measured horizontal displacements at the front slab centre as a function of time. Horizontal displacements at the top of the rear wall are presented in Figure 18 and vertical displacements of the rear wall are shown in Figure 19. According to the measurement result, the vertical maximum displacement value upwards is in this latter test clearly higher $(6 \mathrm{~mm})$ than the corresponding value during the first test $(2 \mathrm{~mm})$. This is believed to be due to the changes in the support system during the test series, which has been newly installed after test V1C.

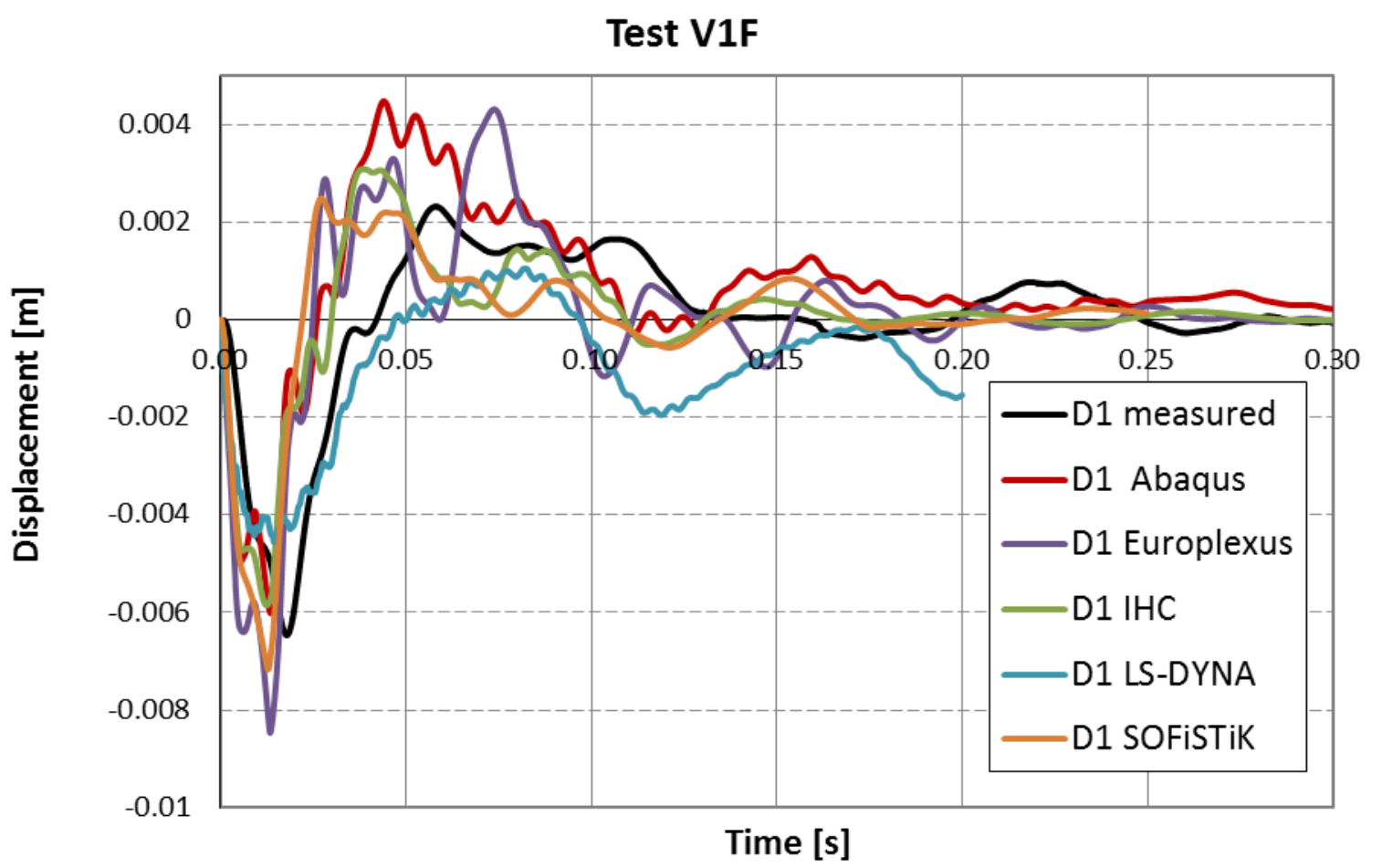

Figure 17. Horizontal displacement at the centre of the front wall in the impact direction. 


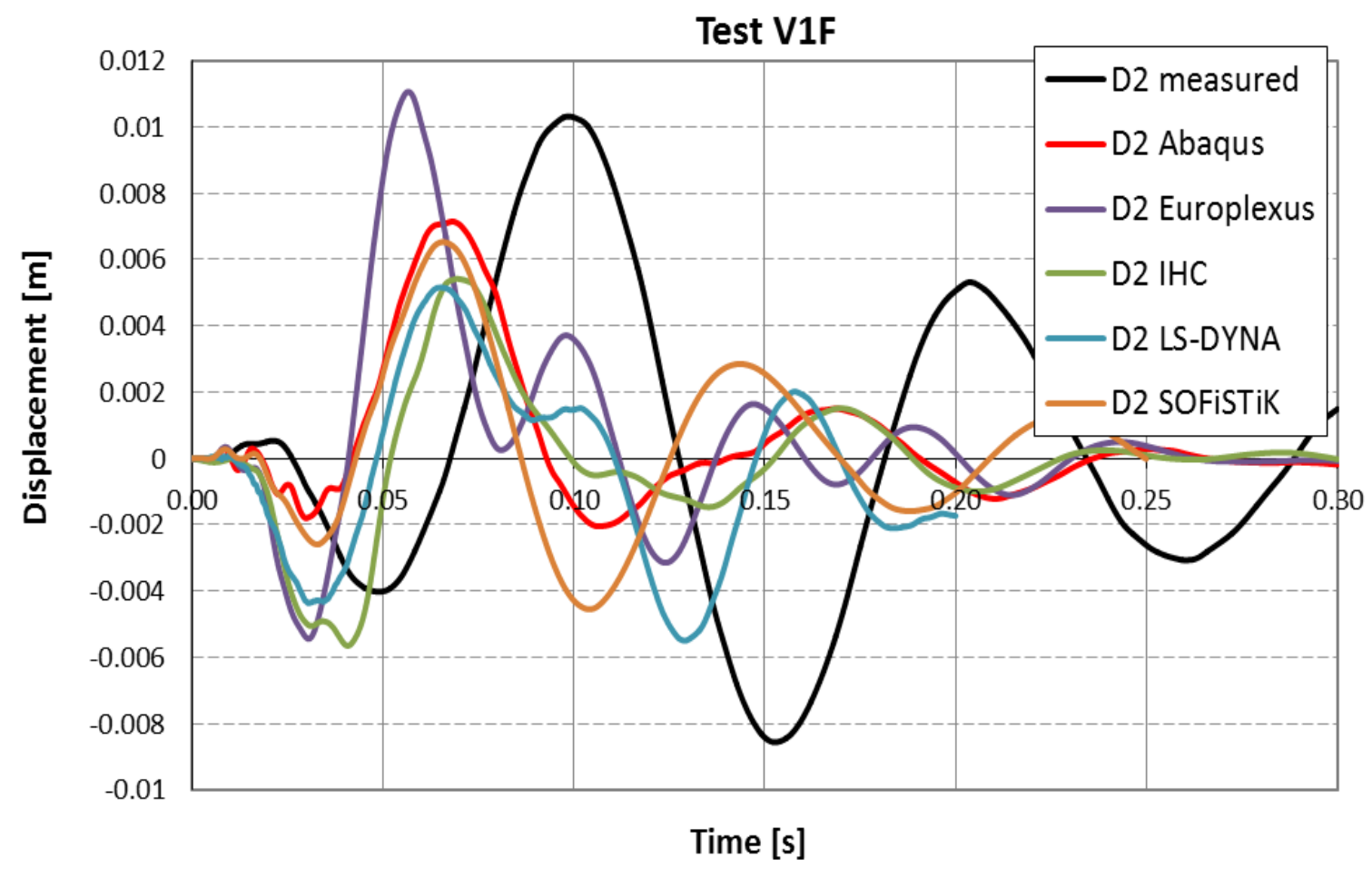

Figure 18. Horizontal displacement at the top of the rear wall in the impact direction.

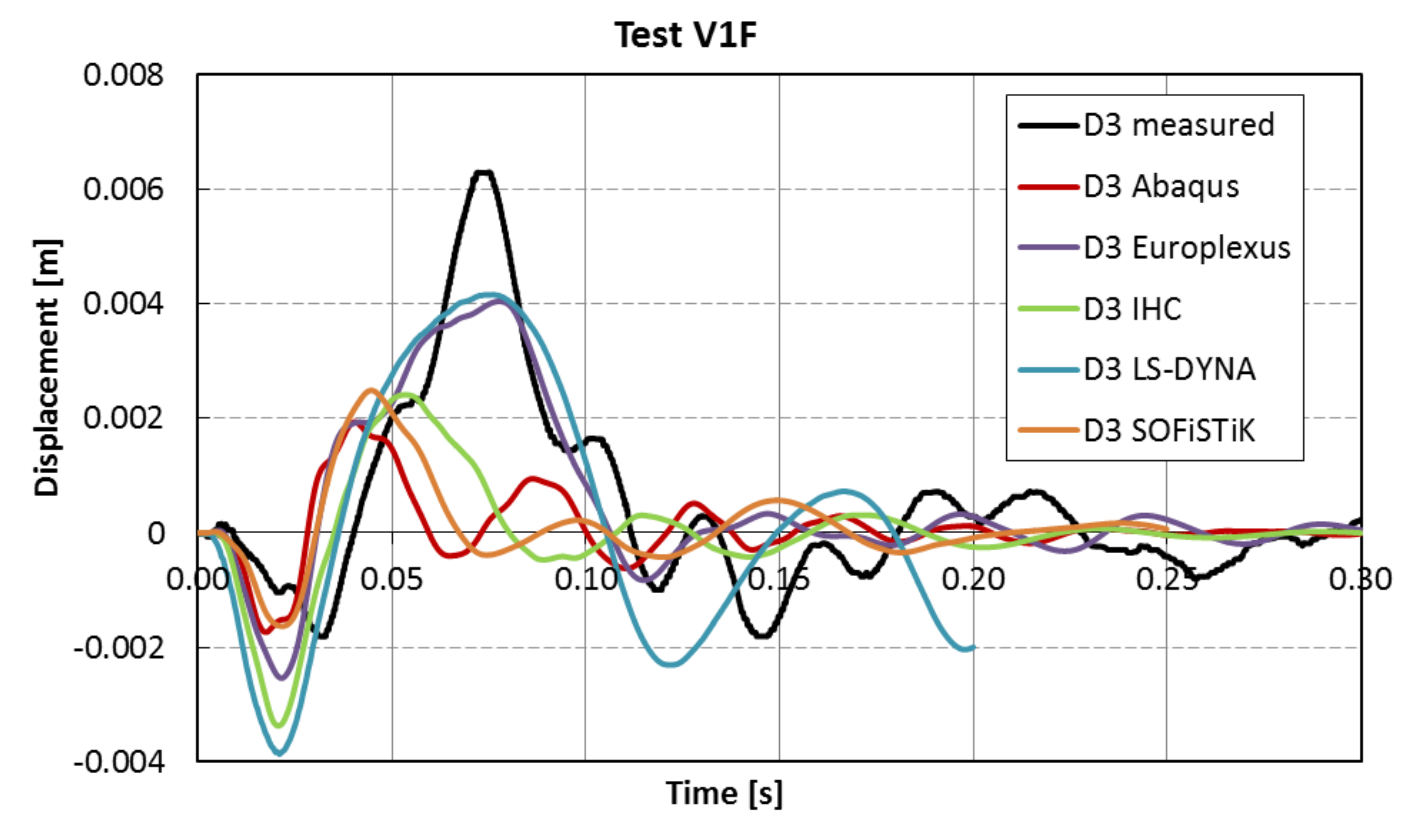

Figure 19.Vertical displacement of the rear wall.

\section{Strain in reinforcement}

The measured and calculated strains in the centre of the front wall, at the impact location, in the back surface vertical reinforcement are shown in Figure 20 and corresponding 
results on horizontal back surface reinforcement are shown in Figure 21. The strain gauge used for measurements in the horizontal direction seems not to be working properly.

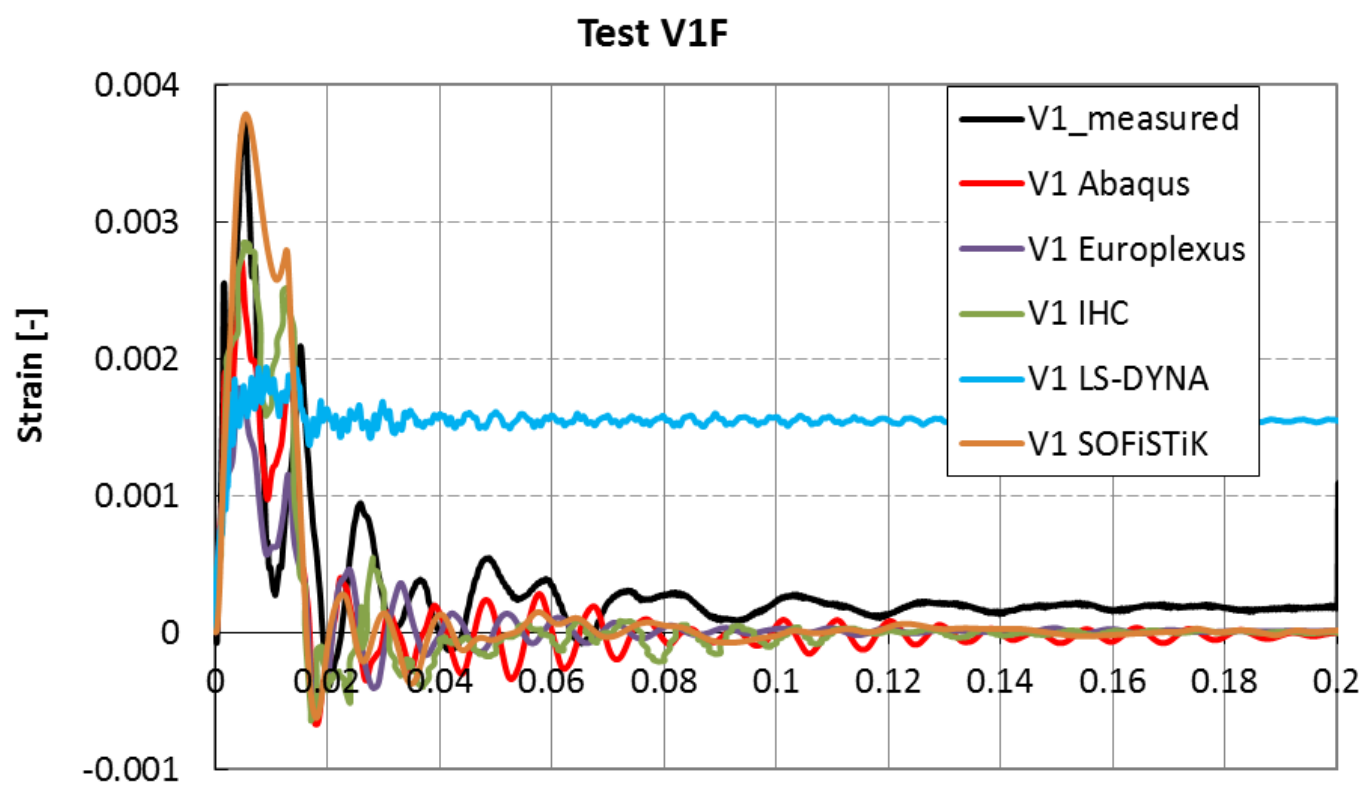

Time $[\mathrm{s}]$

Figure 20. Strain at the vertical back surface reinforcement of the front wall.

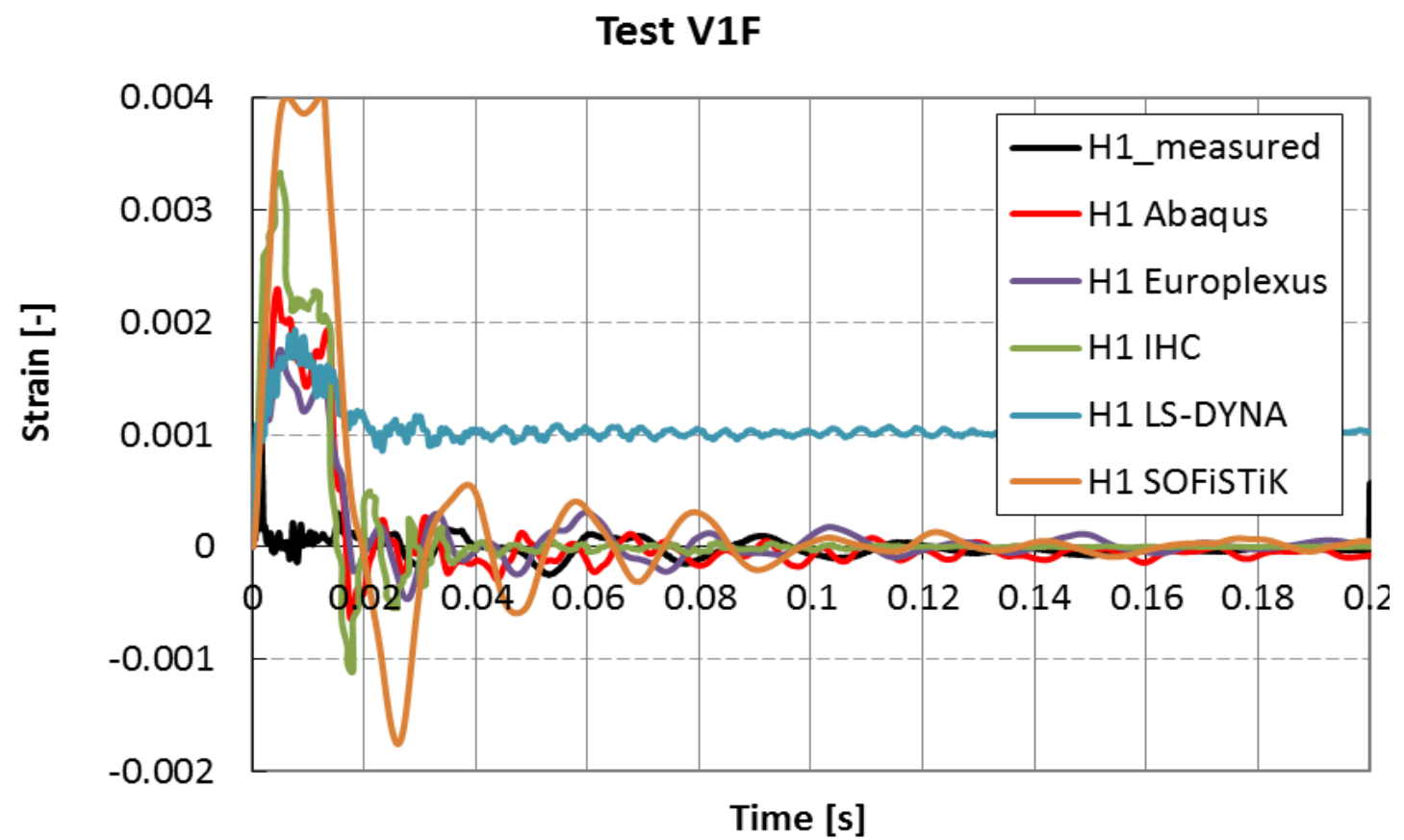

Figure 21. Strain at the horizontal back surface reinforcement of the front wall. 


\section{Response spectra}

Floor response spectra are computed from the measured and calculated acceleration results adopting a 5\% damping. Calculated displacement and acceleration spectra are compared with the corresponding measured values. Acceleration spectra results obtained at location 5, at the top of the rear wall centre, are presented in Figure 22a and corresponding displacement spectra results are shown in Figure 22b. Lower response spectra values were obtained with the fixed support assumption.

Acceleration spectra results obtained at location 3, at the junction of the rear wall and floor, are presented in Figure 23a and corresponding displacement spectra results are shown in Figure 23b.
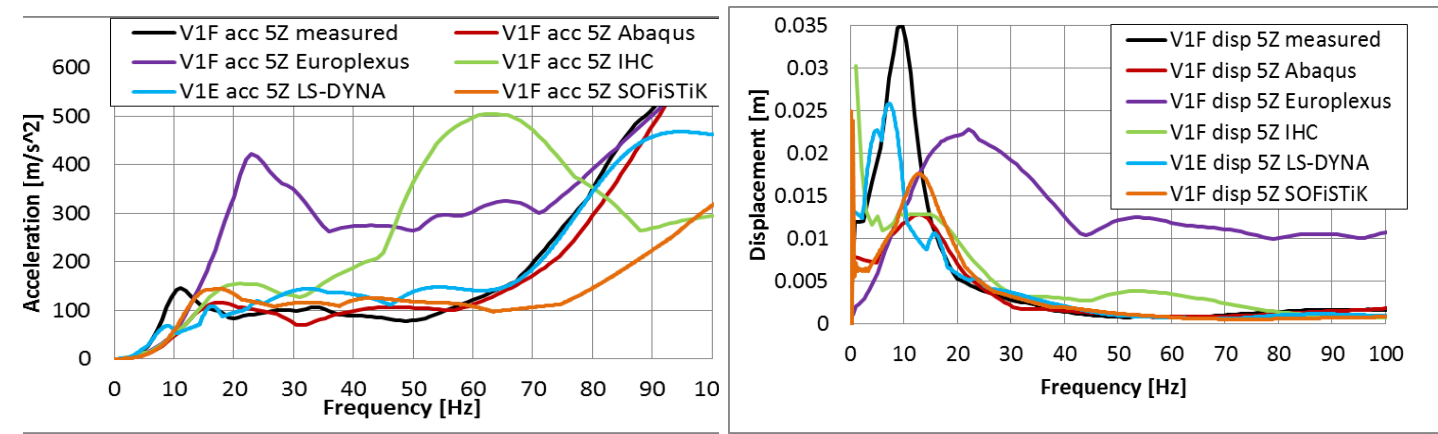

Figure 22. a) Acceleration spectra and b) displacement spectra at the top of the rear wall, horizontal direction.
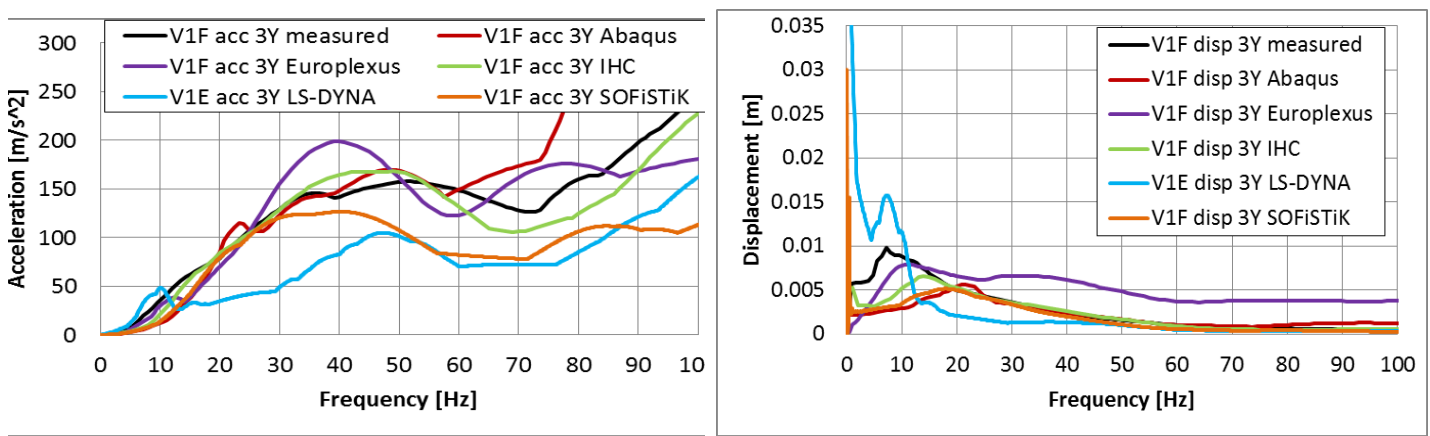

Figure 23. a) Acceleration spectra and b) displacement spectra at the lower edge of the rear wall, vertical direction.

\section{Conclusions}

During the tests, permanent deformations occurred mainly in the front wall. The mockup behaved rather elastically and yielding occurred only in the bending reinforcement at the impact area. The measured maximum strain values in the reinforcement were well below $1 \%$.

It is evident, that the mock-up needs to be supported in order to prevent the rigid body motion. This realistic fact brings in challenges when creating a finite element model of 
the whole system. Although the geometry and mechanical properties of the support structure are available, there very likely are also some nonlinearities due to e.g. gaps and friction. These types of support conditions may also change somewhat during repeated tests as the whole support system loosens. This can actually be observed when comparing the measurement on the vertical displacement of the back wall during the tests V1A and V1F. During the test V1F this displacement was higher than the corresponding value during the first test, where the impact velocity was higher.

Most of the FE-codes in the present study use shell elements. In Abaqus and SOFiSTiK non-linear behaviour of shell section is modelled by dividing the cross section into layers. Reinforcements are also modelled as smeared layers. In Europlexus and IHC an alternative approach is adopted in which the non-linear behaviour of concrete and reinforcement is beforehand homogenized in the shell thickness direction obtaining relations between stress resultants and generalized strains valid for the shell section. In LS-DYNA 3D solid elements for modelling concrete and beam elements for modelling reinforcements are used. The applied force-time functions were in a reasonable agreement. Consecutive impacts were not considered in LSDYNA studies and in Europlexus studies only two consecutive impacts, V1A and V1F were calculated.

\section{Abaqus results}

Calculated results are in a reasonably good agreement with the measurements. The acceleration spectra calculated at the top of the rear wall is in a good agreement with the corresponding measurement result. It should be noted, however, that the bending vibration of the rear wall is not so well predicted. The assumption made for Rayleigh damping parameters here produces rather high damping ratios at the frequencies below $45 \mathrm{~Hz}$.

Actually, the calculated response spectra results of the Test V1F are in a better agreement with the corresponding measurement values than the ones for the Test V1A.

\section{Europlexus results}

Displacements are in relatively good agreement when looking at the whole set of measured curves, for V1A and V1F. The uplift of the rear wall was not well predicted in test V1A, but it is hard to quantify the error when considering the V1F test uplift. The boundaries could have been better modeled, particularly for rolling cylinders at horizontal back pipes and fixed cylinders at the vertical pipes above the front wall, as there is some rotating displacement of the mock-up. Shell modeling is not perfectly suited for this kind of boundary. The calculated spectra have the same shape as the ones obtained from measured accelerations, especially when looking at the whole 0-300 Hz frequency range. This is in agreement with the mock-up having some eigenfrequencies beyond $200 \mathrm{~Hz}$. Even for small displacements, high frequencies can be of some interest. However, pseudo-acceleration of spectra is usually over-estimated in comparison to the test spectra. 


\section{IHC results}

The horizontal deflection history of the rear wall top center is predicted reasonably well. The response spectra values deviate from the rest in the vicinity of $60 \mathrm{~Hz}$. However, the corresponding displacement spectra values are rather small in this range. The possible effect of joint friction on the vertical movement of the rear wall was not attempted to model.

\section{LS-DYNA results}

The slab local impact response (horizontal displacements and bending strains) is predicted reasonably well. The global response of the test body (accelerations and vertical displacement) is not so well predicted; this is mainly due to the challenges in realistically modelling the supporting conditions. The numerical simulations performed using LSDYNA were blind. Therefore, the results obtained here can be improved by calibrating the model assumptions with the experimental data.

\section{SOFiSTiK results}

On the whole, the obtained results represent the observed structural behaviour well. Discrepancies are mainly due to the difficulties raised from the supports of the concrete target. Better simulation results could be achieved with clearer boundary conditions. The deviations of acceleration spectra at high frequencies are especially caused by the smoothed load time functions, which do not include the oscillations of the real impact force function over the crushing period of the missile.

\section{General observations}

These analyses were carried out independently and thus the calculation models vary somewhat. LS-DYNA calculations were carried out blind and fixed supports were assumed. The effect of the different types of assumptions in defining input data can be estimated by comparing the results obtained with LS-DYNA with the other calculation results.

The maximum displacement of the front wall was relatively well predicted with all models, especially for the Test V1A. Bending behaviour of the rear wall was most accurately predicted by the IHC model.

Calculation results obtained with Abaqus and SOFiSTiK models are quite similar. This is probably due to the similar assumptions applied for support modelling. Vertical support by the horizontal back pipes was taken into consideration in these models. In these models also the stiffness value of the horizontal spring at the lower edge of the front wall is only one tenth of the corresponding assumptions for the other models. This lower stiffness value is obtained by taking into consideration also the bending stiffness of the Ibeam (HEB180). According to the sensitivity studies not presented here, these assumptions for spring stiffness at the front wall lower edge are not affecting remarkably the calculation results. 
The damping assumptions applied in these studies varied. In Europlexus and SOFiSTiK models damping was adapted for different parts of the structure while in other models uniform damping properties were used for the whole structure. The amount of energy dissipated due to nonlinear material behaviour varies in the results obtained by the different codes used here. Based on these studies, it is difficult to determine a general damping ratio to be applied in materially nonlinear numerical analyses. Concerning the uncertainties in nonlinear material properties and real support conditions, the obtained calculation results are in reasonable agreement.

Consideration of the results from benchmarking point of view is still on-going. However it is evident that analysed results follow reasonable well test results in main design parameter level such as maximum displacements, accelerations and strains. Also frequency spectra are estimated reasonably well.

\section{Relevance for practice of design}

The main contribution of the performed vibration propagation and damping tests for the simulation practice is the verification of suitability of the constitutive laws implemented in the used commercial as well as in-house FE codes with respect to simulation of the vibration characteristics of a nonlinearly deformed concrete structure. According to aircraft impact studies available to the authors, nonlinear spectra in general are less than such determined by use of a traditional linear approach with modal damping. Only in some cases, the nonlinear spectra are higher particularly in the higher frequency range due to numerical effects e. g. sudden closing cracks. These effects normally are not of importance, because they are connected with very small deformations.

Thus, the availability of validated analysis methods provides the safe utilisation of nonlinear approaches in designing safety related structures also with respect to the design of components by use of response spectra. However, the numerical studies on the presented tests indicate that the sensitivity to the model assumptions is high. Therefore, the preparation of the simulation model and its boundary conditions requires particular care.

\section{References}

[1] A. Vepsä, K. Calonius, A. Saarenheimo, S. Aatola, and M. Halonen. Soft impact testing of a wall-floor-wall reinforced concrete structure. Nuclear Engineering and Design, 311:86-103, 2017. http://dx.doi.org/10.1016/j.nucengdes.2016.10.052

[2] J. D. Stevenson, J. D. Structural Damping Values as a Function of Dynamic Response Stress and Deformation Levels. Nuclear Engineering and Design, 60(2):211-237,1980. https://doi.org/10.1016/0029-5493(80)90238-1

[3] S. H. Chowdhury. Damping characteristics of reinforced and partially prestressed concrete beams. Griffith University, 1999.

[4] A. Saltzmann. Damping characteristics of reinforced and prestressed normal and high-strength concrete beams, PhD thesis, Griffith University. 2002.

[5] A. K. Chopra. Dynamics of Structures, fourth ed. Prentice Hall. London. 1995.

[6] Abaqus Theory Manual. Version 6.14-1. Dassault Systémes. 2014. 
[7] P. Koechlin, and S. Potapov, Global Constitutive Model for Reinforced Concrete Plates. Journal of Engineering Mechanics, 133(3):257-266, 2007. https://doi.org/10.1061/(ASCE)0733-9399(2007)133:3(257)

[8] K.J. Bathe and E.N. Dvorkin. A four-node plate bending element based on Mindlin/Reissner plate theory and mixed interpolation. International Journal for Numerical Methods in Engineering, 21:367-383, 1985. https://doi.org/10.1002/nme.1620210213

[9] A. Ibrahimbegovic and F. Frey. Stress resultant finite element analysis of reinforced concrete plates. Engineering Computations, 10:15-30, 1993. https://doi.org/10.1108/eb023892

[10] Koechlin, P. Modèle de comportement membrane-flexion et critère de perforation pour l'analyse de structures minces en béton armé sous choc mou, Thèse de doctorat de l'Université Pierre et Marie Curie - Paris VI.S. H. 2007.

[11] LS-DYNA, Keyword User's Manual, Version LS-DYNA R8.0. Livermore Software Technology Corporation (LSTC). 2015.

[12] SOFiSTiK, Analysis Programs, Version 30.0, SOFiSTiK AG.Oberschleißheim. 2014.

[13] Calenberg Ingenieure GmbH. bi-Trapez Bearing®. http://www.calenbergingenieure.com/pr-building-construction-da-elastomeric-impact-sound-insulationbi-trapez-bearing.htm/ (accessed 6.7.2016)

[14] J. D. Riera. On the stress analysis of structures subjected to aircraft impact forces. Nuclear Engineering and Design, 8:415-426, 1968. https://doi.org/10.1016/00295493(68)90039-3

Arja Saarenheimo

VTT Technical Research Centre of Finland Ltd.

Kemistintie 3, Espoo, P.O.Box 1000, FI-02044 VTT, Finland

arja.saarenheimo@vtt.fi

Michael Borgerhoff

Stangenberg und Partner Consulting Engineers

Viktoriastraße 47, 44787 Bochum, Germany

borgerhoff@stangenberg.de

Kim Calonius

VTT Technical Research Centre of Finland Ltd. Kemistintie 3, Espoo, P.O.Box 1000, FI-02044 VTT, Finland

kim.calonius@vtt.fi

Anthony Darraba

EDF Electricité de France

12-14 Avenue Dutriévoz, 69628 Villeurbanne, France

anthony.darraba@edf.fr 
Alexandre Hamelin

EDF Electricité de France

12-14 Avenue Dutriévoz, 69628 Villeurbanne, France

alexandre.hamelin@edf.fr

Sara Ghadimi Khasraghy

Basler \& Hofmann AG, Consulting Engineers

Forchstrasse 395, 8008 Zürich, Switzerland

sara.ghadimi@baslerhofmann.ch

Amin Karbassi

Basler \& Hofmann AG, Consulting Engineers

Forchstrasse 395, 8008 Zürich, Switzerland

amin.karbassi@baslerhofmann.ch

Christian Schneeberger

Swiss Federal Nuclear Safety Inspectorate ENSI

Industriestrasse 19, CH-5200 Brugg,Switzerland

christian.schneeberger@ensi.ch

Matthias Stadler

Stangenberg und Partner Consulting Engineers

Viktoriastraße 47, 44787 Bochum, Germany

m.stadler@stangenberg.de

Markku Tuomala

Consultant

Pakkamestarinkatu 3C, 00520 Helsinki 52, Finland

markku.tuomala@professori.fi

Pekka Välikangas

STUK Radiation and Nuclear Safety Authority

Laippatie 4, B.O.Box 14, FI-00881, Finland.

pekka.valikangas@stuk.fi 